Accepted Manuscript

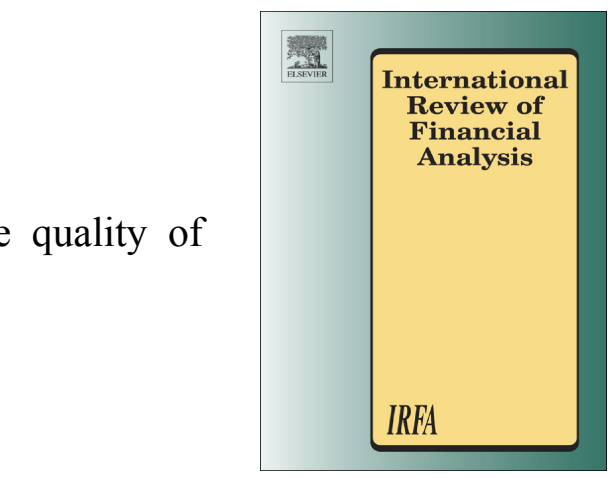

Patrycja Klusak, Rasha Alsakka, Owain ap Gwilym

PII: $\quad$ S1057-5219(18)30779-8

DOI: $\quad$ https://doi.org/10.1016/j.irfa.2019.06.004

Reference: $\quad$ FINANA 1365

To appear in: $\quad$ International Review of Financial Analysis

Received date: $\quad 29$ November 2018

Revised date: $\quad 11$ April 2019

Accepted date: $\quad 7$ June 2019

Please cite this article as: P. Klusak, R. Alsakka and O.a. Gwilym, The impact of ESMA regulatory identifiers on the quality of ratings, International Review of Financial Analysis, https://doi.org/10.1016/j.irfa.2019.06.004

This is a PDF file of an unedited manuscript that has been accepted for publication. As a service to our customers we are providing this early version of the manuscript. The manuscript will undergo copyediting, typesetting, and review of the resulting proof before it is published in its final form. Please note that during the production process errors may be discovered which could affect the content, and all legal disclaimers that apply to the journal pertain. 


\title{
The impact of ESMA regulatory identifiers on the quality of ratings
}

Patrycja Klusak $^{\mathrm{a}}$, Rasha Alsakka ${ }^{\mathrm{b}, *}$, Owain ap Gwilym ${ }^{\mathrm{b}}$,

${ }^{a}$ Norwich Business School, University of East Anglia, NR4 7TJ, UK.

${ }^{\mathrm{b}}$ Bangor Business School, Bangor University, LL57 2DG, UK

This version: $11^{\text {th }}$ April 2019

\begin{abstract}
This paper investigates the impact of the introduction of ESMA credit rating identifiers on the quality of ratings. These identifiers form part of the disclosure requirements placed upon credit rating agencies (CRAs) since 2012 under a new EU regulatory regime and have not featured in any prior empirical literature. Rating informativeness is gauged from bond market data. Using a rich dataset of sovereign rating actions by the three major CRAs for 70 countries during the period 2006-2016, we find that the ESMA requirement for identifiers yields varying outcomes across downgrades and upgrades. The rating quality associated with downgrades by Moody's improves, whereas upgrades by S\&P, Moody's and Fitch are of lower quality. These results are consistent with greater conservatism in rating policies after the regulatory reforms. ESMA's additional focus on analyst location does not reveal any consistent difference in the quality of ratings.
\end{abstract}

Keywords: Rating agency regulation; ESMA identifiers; Quality of ratings; Analyst location. JEL classification: G15; G24.

* Corresponding author. Tel.: +44 (0) 1248383571.

E-mail addresses: p.klusak@uea.ac.uk (P. Klusak), r.alsakka@bangor.ac.uk (R. Alsakka), owain.apgwilym@bangor.ac.uk (O.ap Gwilym). 


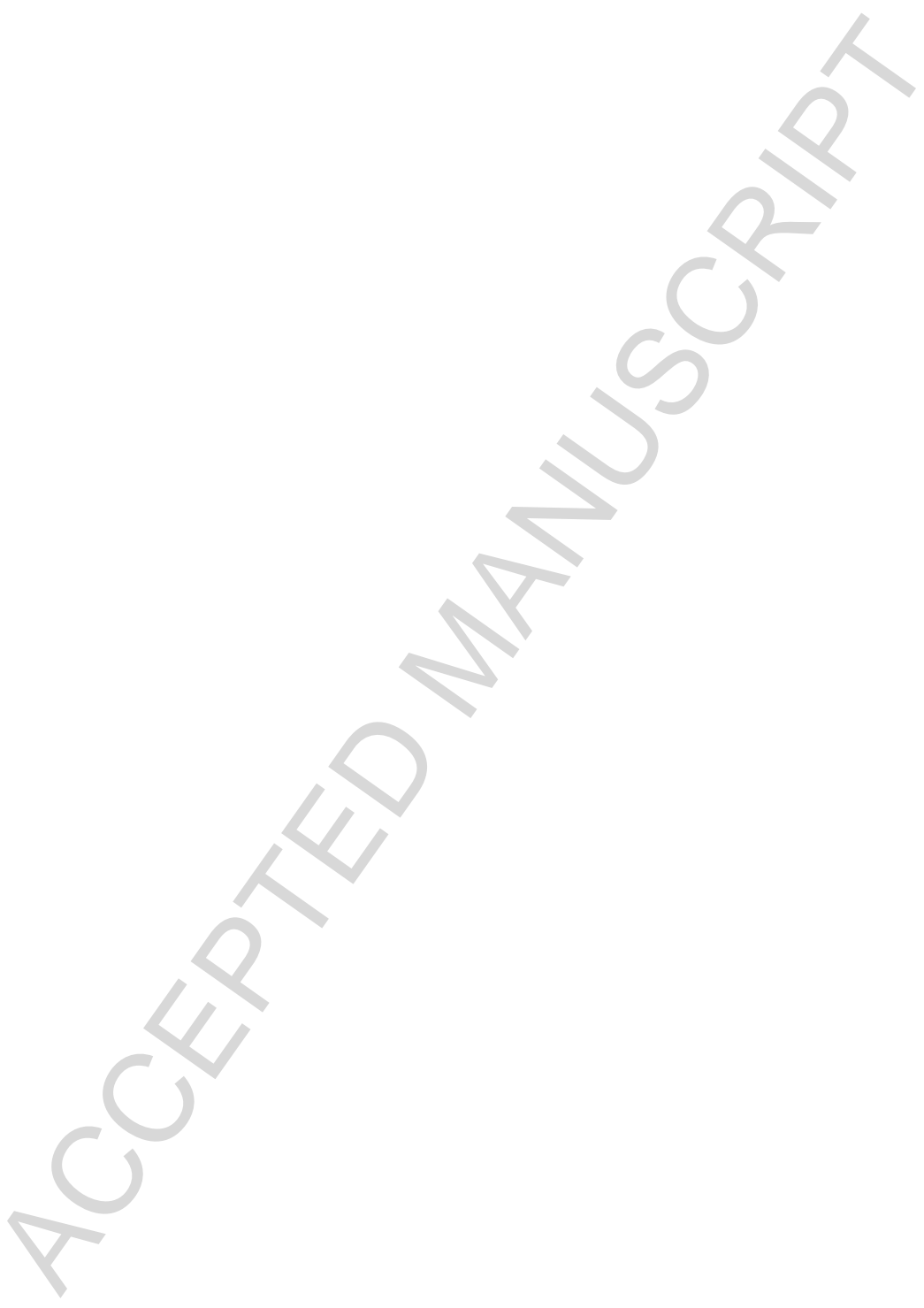




\title{
The impact of ESMA regulatory identifiers on the quality of ratings
}

\author{
This version: $11^{\text {th }}$ April 2019
}

\begin{abstract}
This paper investigates the impact of the introduction of ESMA credit rating identifiers on the quality of ratings. These identifiers form part of the disclosure requirements placed upon credit rating agencies (CRAs) since 2012 under a new EU regulatory regime and have not featured in any prior empirical literature. Rating informativeness is gauged from bond market data. Using a rich dataset of sovereign rating actions by the three major CRAs for 70 countries during the period 2006-2016, we find that the ESMA requirement for identifiers yields varying outcomes across downgrades and upgrades. The rating quality associated with downgrades by Moody's improves, whereas upgrades by S\&P, Moody's and Fitch are of lower quality. These results are consistent with greater conservatism in rating policies after the regulatory reforms. ESMA's additional focus on analyst location does not reveal any consistent difference in the quality of ratings.
\end{abstract}

Keywords: Rating agency regulation; ESMA identifiers; Quality of ratings; Analyst location.

JEL classification: G15; G24. 


\section{Introduction}

A growing body of literature investigates US regulatory reforms relating to credit rating agencies (CRAs) and the effects of these changes on rating quality (e.g. Behr et al., 2018). Rating quality is important for international financial stability, because ratings are strongly embedded in many banking and investment regulations and therefore affect the welfare of both borrowers and investors (e.g. Bae et al., 2015). We focus on a unique European regulatory aspect which does not arise in the US regime. In 2012, the European Securities and Markets Authority (ESMA) introduced new regulations, stipulating that credit ratings must be accompanied by identifiers distinguishing between ratings issued by analysts within the EU, versus those issued in countries that qualify as endorsed jurisdictions. For the ratings to be classed as 'endorsed', the analyst must be located in a jurisdiction which has a comparably stringent regulatory regime to that of the EU (EC, 2011). Further, only ratings accompanied by these identifiers can be used for regulatory purposes after April 2012. ${ }^{1}$

ESMA (2011a) anticipates that using identifiers should assist in dissemination of information amongst investors and support supervisory integration of CRAs. This in turn should benefit the functioning of financial markets and their stability, and protect EU investors through equivalence in the quality of ratings across countries. A strict legal and supervisory framework aims "to ensure that ratings are independent, objective, and of adequate quality" in order to underpin the confidence of financial markets and investors (ESMA, 2017b). ESMA's belief is that compliance with these rules will have improved the quality of ratings used within Europe. To date, there is no published evidence on this. We assess the impact of these identifier rules on the quality of ratings, using a dataset of sovereign ratings assigned by Moody’s, S\&P and Fitch for 70 countries from 2006-2016.

\footnotetext{
${ }^{1}$ ESMA (2017a) state that more than two thirds of the ratings used for regulatory purposes in Europe are 'endorsed'.
} 
It is an open question whether the introduction of rating identifiers could have any consistent or meaningful impact on rating quality. It is important to investigate such a substantial policy initiative, especially with no prior evidence being available on this question. We also specifically examine whether the location of rating analysts (in the EU versus outside the EU) has any significant impact on changes in rating quality. Investigation of the effects of ESMA's endorsement rules is important because such rules could potentially signal enhanced credibility of CRAs' opinions. Studying the impact of these rules informs future policies and regulations and identifies whether their effect is contradictory or unanticipated.

Furthermore, our paper utilizes sovereign ratings, offering a significant contribution to the literature because the quality of sovereign ratings is highly important for practitioners and governments alike. Sovereign ratings have greater impact and influence in comparison with the corporate and structured ratings investigated by some recent literature on CRA regulation (e.g. Bae et al., 2015; Behr et al., 2018; Bolton et al., 2012; Dimitrov et al., 2015; Flynn and Ghent, 2018; Hill et al., 2018). Sovereign ratings reflect a country's willingness and ability to pay its obligations (e.g. Baum et al., 2016; Cai et al., 2019). They directly affect a country's cost of borrowing and foreign direct investment flows (e.g. Cai et al., 2019), and indirectly affect the cost of firms' credit via the sovereign ceiling on bank and corporate ratings (Almeida at al., 2017; Arezki et al., 2011; Borensztein et al., 2013; Chen et al., 2016). The recent sovereign debt crisis in Europe has emphasized the consequences of spillovers of sovereign rating actions across countries and asset classes (e.g. Baum et al., 2016; Hill et al., 2018), which further strengthens the importance of this study.

The existing empirical evidence on the effects of regulation on CRAs considers nonsovereign ratings and takes the perspective of changing competition between CRAs (Bae et al., 2015; Behr et al., 2018). We offer a different approach focusing on the direct effect of 
regulation on rating quality, more in line with a theoretical paper by Opp et al. (2013). Although sovereign ratings represent the highest proportion of the total outstanding ratings across all rating segments, the competition level between CRAs for sovereign ratings is the lowest across these segments (ESMA, 2016).

Most previous studies assessing the impact of regulatory initiatives on the quality of ratings focus on US regulations (see Behr et al., 2018; Bongaerts et al., 2012; Dimitrov et al., 2015; Doherty et al., 2012). In addition, most prior research addresses time periods before the EU regulatory regime was introduced. For instance, Behr et al. (2018) use a data sample between 1973 and 1982, Bongaerts et al. (2012) utilize a sample for 2002 to 2008, and Doherty et al.'s (2012) sample is from1989 to 2000. Becker and Milbourn (2011) apply a sample from 1995 to 2006 whereas Kisgen and Strahan (2010) use the period between 2001 and 2005. Moreover, our paper examines the direct feedback of regulatory authorization on ratings quality in contrast with previous studies assessing the price impact of regulation (e.g. Kisgen and Strahan, 2010).

Attaining information and measuring creditworthiness is costly and time consuming for investors, therefore many entrust this task to the CRAs. According to Becker and Milbourn (2011), inter alia the quality of ratings rests on their ability to communicate information to market participants by maintaining a stable meaning of risk classification. Low quality ratings might harm the information diffusion of ratings unless all market participants are well informed. If investors are not able to extract reliable information from ratings, this lessens their value and reduces the benefits for the financial system (Bolton et al., 2012). Additionally, low quality ratings complicate regulations and make contracting with ratings more difficult. Finally, ratings quality is at the centre of the policy agenda because it is closely related to banking regulation (capital adequacy requirements in particular). 
In this study, following Bae et al. (2015), Becker and Milbourn (2011), Behr et al. (2018) and Dimitrov et al. (2015), the quality of ratings is captured by the information content which surfaces through the ability of ratings to explain bond yields. The market functions more effectively when ratings are more aligned with bond yields. For instance, when ratings accurately reflect the risk of an issuer, and therefore correlate highly with its bond yields, they have the power to protect investors by reducing information asymmetries (Flynn and Ghent, 2018). Therefore, our research questions are: (i) Does the quality of ratings (captured by their informativeness) change after the introduction of ESMA identifiers?, and (ii) Does the location of rating analysts (in the EU versus outside the EU) have an impact on any changes in the quality of ratings?

To preview the findings, ESMA's identifier disclosure rules have not fully succeeded in achieving the aim of improved quality of ratings. There are differences in the quality of ratings in the period after the endorsement regime was introduced. We find poorer rating quality (less informative ratings) for positive rating actions by all CRAs after the introduction of the identifiers, while better quality (more informative) ratings are reported for Moody's negative actions. However, there are mixed findings on the impact of the specific location of rating analysts on the informativeness of sovereign ratings. This outcome is not unexpected because ratings should only reflect factors related to the expected debt servicing by the issuer, and not to be strongly affected by the location of rating analysts. Specifically, there is limited evidence that positive events by Fitch and Moody's are less informative when the relevant analysts are located outside the EU (with EE identifiers), whereas S\&P positive events are of lower quality when their rating analysts are based in the EU. In contrast, there is some evidence of better quality ratings for Fitch negative events when their analysts are located outside the EU. 
Such differences across CRAs are consistent with the unequal market impacts of rating signals by different CRAs reported in previous literature (Afonso et al., 2012; Arezki et al., 2011; Baum et al., 2016; Bedendo et al., 2018; Livingston et al., 2010). Our results, to a large extent, support those of Behr et al. (2018) and Dimitrov et al. (2015), in terms of unintended consequences of CRA regulation in the US, and are in line with the theoretical predictions of Opp et al. (2013).

Despite many studies of CRA regulations (e.g. Becker and Milbourn, 2011; Behr et al., 2018; Bongaerts et al., 2012; Dimitrov et al., 2015), no previous study has investigated the impact of ESMA rating identifiers and the location of rating analysts on rating quality. This paper is therefore able to offer many important contributions to the literature.

The structure of this paper is as follows. Sections 2 and 3 introduce the background of the EU CRA regulatory regime along with a summary of the relevant academic literature. Section 4 presents the data and descriptive statistics then Section 5 describes the methodology. Section 6 reports empirical results and Section 7 concludes the study.

\section{Regulatory developments}

\subsection{European CRA regulation}

EU CRA regulatory initiatives aim at reducing conflicts of interest, overreliance on ratings and spillover effects, while increasing independence and soundness of rating processes and improving quality of rating methodologies and ratings (ECB, 2012). ESMA believe that endorsing ratings from non-EU countries enables supervisory integration of the CRAs. Greater co-operation between outside supervisors benefits the functioning of financial markets and protects investors in the EU (ESMA, 2011a). According to the EC, a CRA operating in a non-EU country needs to conform to the EU level of supervisory expectations. 
The usage of rating identifiers differentiates between ratings assigned inside/outside the EU. The regulators try to ensure that, in the current framework, "users of ratings in the EU would benefit from equivalent protections in terms of a CRA's integrity, transparency, good governance and reliability" (ESMA, 2017a). The recent financial crisis showed that there is a need for stronger and more stable markets and for investor protection that is transferable across states (ESMA, 2012). When assessing the equivalence of non-EU countries, the rules incorporate all provisions of the EU CRA Regulation. ${ }^{2}$ The equivalence in quality of ratings and methodologies (supported by the identifiers) should help to protect financial market stability. High quality ratings lead to improved efficiency of capital markets and improve transparency and competition (ESMA, 2011b).

In seeking to influence the quality of ratings, ESMA requires CRAs to be registered as a regulated CRA in the EU to be able to endorse ratings (into the EU) which are originated outside the EU. Initially, the equivalence regime required endorsed ratings to be assigned in a jurisdiction which operates a regulatory regime for CRAs which is "at least as stringent as the relevant EU rules" (EC, 2011). The endorsement permits CRAs which operate and are registered in the EU to authorize ratings of entities which are part of their own groups and which operate outside the EU. Both the ratings assigned in the EU as well as ratings from non-EU countries but endorsed based on the equivalence regime can be used for regulatory purposes (e.g., by banks). ${ }^{3}$

ESMA (2017b) provides an update of the initial Guidelines on Endorsement, which are a reflection of issues arising with the regime. It provides an updated methodological framework

\footnotetext{
${ }^{2}$ These include: (i) extent of regulatory and supervisory framework; (ii) corporate governance; (iii) conflict of interest; (iv) organizational constraints; (v) quality of methodologies and ratings; (vi) disclosure rules; (vii) supervision and enforcement rules.

${ }^{3}$ The equivalence tests conducted by ESMA, announced before end-April 2012, concluded that ratings originating from Argentina, Australia, Brazil, Canada, Hong Kong, Japan, Mexico, Singapore and the United States fulfil this requirement. After that date, market participants in the EU (e.g., banks calculating capital adequacy positions) were forbidden from using ratings originating from unrecognized jurisdictions for regulatory purposes (ESMA, 2012).
} 
to evaluate the non-EU countries' legal and regulatory frameworks. The main changes relate to obligations of the endorsing CRA, ESMA's supervisory powers and objective reasons for using endorsed ratings. From 2018, the responsibility for ensuring that a CRA's internal operations in a non-EU country are as stringent as those outlined by EU requirements lies with the endorsing CRA. It is no longer the case that the rating issued in the country meeting equivalence tests (e.g., Argentina) automatically meets this criterion. In addition, "ESMA clarifies that it has the power to request periodical information directly from the endorsing EU CRA regarding endorsed credit ratings and the conduct of the third country CRA".

\subsection{US versus EU regulatory reforms}

One could be concerned about a possibility that the changes in quality of ratings, attributed to ESMA identifiers, might be influenced by elements of the Dodd-Frank Act (DFA) which affect CRAs in the US from July 2010. In this section, we discuss the differences between the US and EU regulatory regimes for CRAs, to further strengthen the motivation of this study. Importantly, the DFA does not make any reference to the location of analysts. The section of the DFA relating to CRA analysts only considers the knowledge and qualification standards that the analysts are required to meet, e.g. training, experience, and competence for the rating segment (Dodd-Frank Act 936, 2010).

Although the rules aiming at CRAs in Europe and the US are similar, the European regulation is more pronounced with respect to sovereign ratings. CRAs were accused of worsening the European debt crisis by downgrading the ratings of Eurozone sovereigns too far and too fast. EU regulations aim for increased transparency and completeness of sovereign rating methodologies, and to address the timing of rating actions. For example, sovereign debt ratings are to be assessed every six months and with detailed explanations for the rationale behind the rating actions. The CRAs are permitted to issue unsolicited ratings 
for sovereigns up to three times per year with their timing specified in advance. Sovereign ratings are required to be published after the close of business (Friday) and minimum one hour before markets open again (Monday) (OJEU, 2013). US regulation does not require CRAs to announce when releasing sovereign ratings and there is no provision requesting their solicitation status (ESMA, 2017c). As of May 2013, CRAs in the EU are forbidden from making policy recommendations, prescriptions or guidelines when releasing sovereign ratings and/or outlooks (OJEU, 2013). Another difference between the two regimes is the effort towards tackling overreliance on ratings by market participants, which is attributed to strong hardwiring of CRA actions in investment rules and regulations (Kisgen and Strahan, 2010). US regulators took significant steps to decrease reference to ratings (Bedendo et al., 2018). Although the BIS (2014) proposal to revise the standardised approach for credit risk aimed to erase the references to external credit ratings, it later restored and allowed the use of external ratings in Basel III post-crisis regulatory reforms (BIS, 2017).

Another area of major differences between the two regimes involves quality of methodologies and of credit ratings (ESMA, 2017c). For instance, the US framework does not require CRAs to provide the credit rating information to the rated entity prior to publication in order to identify possible errors, but this is a requirement in Europe.

Additional differences can be found with respect to disclosure rules (ESMA, 2017c). US regulation does not require the solicitation status of the rating released to be identified, which is the case in European regulation. Moreover, the EU (not the US) regulation requires CRAs to disclose, on their websites and to the supervisor, information about all entities or debt instruments submitted for their initial review or preliminary rating. Furthermore, CRAs in the EU (not in the US) are required to provide details of rating fees.

The above comparison of the regulatory rules provides confidence that the ESMA identifiers introduced in 2012 were not foreseen/captured by changes in the US regulation. 


\section{Relevant credit rating literature}

Although credit ratings play a vital role in financial markets and the literature on credit ratings is voluminous, research which specifically investigates ratings quality is surprisingly limited. The majority of closely related prior studies concentrate on the information content of ratings, which is approached by considering the association between credit ratings (or their changes) and bond yields (or their changes). Becker and Milbourn (2011) define the quality of ratings as their ability to transmit reliable information to market participants and their ability to categorize the risk of a rated instrument. Classification is especially important for regulation due to its requirement for stable interpretations of ratings used in contracts and capital requirements. In other papers, the concept of rating accuracy is used. For example, Flynn and Ghent (2018) measure rating quality as the gap between the level of ratings of entrant versus incumbent CRAs.

Other studies focus on the effect of ratings on the supply of debt capital with the use of leverage as a dependent variable. Kisgen and Strahan (2010) investigate the regulatory influence of various levels of ratings, rather than the impact of having a rating, on bond yields. The authors establish that rating-contingent regulation influences a firm's cost of debt capital (bond yields) asymmetrically. Only higher ratings from a newly certified CRA correspond to a decline in firms' cost of capital. These results are corroborated by Bongaerts et al. (2012), who state that Fitch's ratings are important mainly for regulatory reasons as a tie-breaker between differing ratings of Moody's and S\&P.

The impact of regulation on the rating industry is mainly examined by considering the entry of a regulated CRA and the corresponding effect of increased competition on the rest of the CRA industry. Bolton et al. (2012) and Dimitrov et al. (2015) suggest that the overall 
quality of ratings drops with increased competition. Bolton et al. (2012) conclude that increased competition between CRAs might lead to increased rating shopping and a consequent reduced wealth effect. Studying the entry of new CRAs into structured ratings, Flynn and Ghent (2018) find that entrant CRAs issue higher ratings than the incumbent firms, a strategy used to win business. This results in rating shopping on the part of issuers.

Behr et al. (2018) suggest that the restricted competition and increased importance of ratings due to their hardwiring in banking and investment regulations can have a detrimental effect on rating quality. The authors find that SEC regulation from 1975 increased the barriers to entry and captured a customer base for certified CRAs, which changed their incentives and created a tendency towards inflated bond ratings. In contrast, Doherty et al. (2012) study insurance ratings and find that the new entrant CRA chooses higher standards than the incumbent companies. They conclude that increased competition results in improved precision of default rate estimates. Similarly, Bae et al. (2015) cast doubt on the view that competition leads to inflated ratings in the corporate bond market. By revisiting the study of Becker and Milbourn (2011), these authors find that their results of rating inflation suffer from endogeneity caused by unobservable industry effects.

There is only very scarce literature on the effect of CRA regulation, which does not primarily emphasise a competition perspective. A theoretical paper by Opp et al. (2013) suggests that ratings-contingent regulation diminishes the incentives of CRAs in information provision. Opp et al. (2013) argue that there is known to exist a threshold level of regulatory gain, beyond which the regulatory arbitrage brings in the same advantage as delegated information attainment by the CRA. When issuers receive favourable rating treatment and its economic advantage is higher than that of obtaining information, regulation causes the collapse of the information provision process and leads to ratings inflation. They suggest that 
it might be cost-effective for CRAs to release lower-quality ratings instead of dealing with complicated asset structures (e.g. for banks).

\section{Data $^{4}$}

\subsection{Data sources}

The bond characteristics and pricing data are collected from Bloomberg L.P. The selection criteria include publicly placed, unsecured, straight sovereign bonds with fixed coupon, remaining maturity between 1 to 30 years and issued in US dollars. We exclude structured notes, inflation-linked notes, hybrid or dual-currency bonds and restructured debt. Only bonds with the pricing information available (historical data such as YTM) are retained. We match rating events with the adequate bond spread information and investigate any outliers. ${ }^{5}$ The dataset comprises 823 rating events ${ }^{6}$ assigned by three CRAs for 70 sovereigns. ${ }^{7}$

Bond spreads, in basis points, are calculated by taking the difference between the yield to maturity of the sovereign bond subject to the rating action and the yield to maturity of the comparable US benchmark bond. We match each sovereign bond with the benchmark bond based on the closest remaining maturity and coupon amount. The 70 sovereigns are represented by 159 individual sovereign bonds. We use 76 US bonds as benchmarks for spread calculations. The long-term foreign-currency ratings are gathered from the three CRAs' publications. The rating actions are matched with the bond data. Data for multiple bonds is normally observable on the day of the rating action. We select the bond with the

\footnotetext{
${ }^{4}$ We discuss Data prior to Methodology in order to explain and define variables and data issues that will be required in the methodology.

${ }^{5}$ Outliers in sub-samples are identified using the MM-robust regression method and are excluded before estimation. The rule applied here is that robust standardized residuals (vertical dimension outlier) which lie outside the range $[-20,+20]$ and $[0,20]$ of the robust distance of the distribution (horizontal dimension outlier) are excluded from the analysis. As a result, $5 \%$ of the data sample was discarded.

${ }^{6}$ Because we use US Treasury bonds as a benchmark for the sovereign credit spread, we exclude the few rating events for the US within the sample period.

${ }^{7}$ The starting sample includes sovereign ratings for 91 countries, and then is reduced to 70 countries on the basis of bond data availability. These 70 countries reflect large developed and emerging countries.
} 
highest issue amount per sovereign on the particular rating event date. For any given rating event, only one bond is considered.

\subsubsection{Descriptive statistics}

We identify rating events using a comprehensive credit rating scale (58-CCR point) which includes ratings, watch and outlook status, as follows: $\mathrm{AAA}=58, \mathrm{AA}+=55 \ldots \mathrm{CCC}-$ $=4, \mathrm{C} / \mathrm{SD} / \mathrm{CC} / \mathrm{D}=1$. Then, for positive watch (outlook) we add $+2(+1)$ whereas for negative watch (outlook) we subtract 2 (1), respectively (see Appendix A). Table 1 presents statistics on the credit events in our sample. Overall, actions of one CCR point constitute the largest share among all CRAs (exceeding 22\% and 19\% for positive and negative events respectively). There are 152 (194), 141 (104) and 116 (116) upgrades (downgrades) by S\&P, Moody's and Fitch respectively. The highest average numerical rating, based on the 58-CCR numerical rating scale, is by Fitch (29, equivalent to BB+/BBB-), followed by Moody's (28, $\mathrm{BB}+)$ and $\mathrm{S} \& \mathrm{P}(27, \mathrm{BB} / \mathrm{BB}+) . \mathrm{S} \& \mathrm{P}$ releases the highest proportion of downgrades against upgrades in all time periods. ${ }^{8}$ The implication that $\mathrm{S} \& \mathrm{P}$ is the more conservative CRA corresponds with prior literature (e.g., Flynn and Ghent, 2018). S\&P assigned the highest proportion of 2 and above CCR-point downgrades (16\%). Fitch has the highest proportion $(12 \%)$ of positive actions by more than 2 CCR points.

We also split the sample into the pre-identifier (Jan 2006-April 2012) and post-identifier (May 2012-June 2016) periods. From the total of 823 events, 426 (397) actions occur in the pre-identifier (post-identifier) period. Positive (negative) actions in the pre-identifier period constitute $54 \%$ (46\%) of events, and they amount to $46 \%$ (54\%) in the post-identifier period. The average rating is higher in the pre-identifier period, although the sample size for both periods is quite balanced, indicating that ratings are less inflated after the regulation. Given that the pre-identifier period includes the outbreak of the global financial crisis and the

\footnotetext{
${ }^{8}$ However, in the post-identifier period, Moody's and Fitch issue 52\% downgrades against $48 \%$ upgrades.
} 
European sovereign debt crisis, one could anticipate the reverse i.e., ratings to be higher after May 2012. ${ }^{9}$

Table 2 illustrates statistical properties of three event samples. The variables in the three CRAs' sub-samples have similar distributions (e.g., term to maturity, coupon rate, and issuance amount). These commonalities allow easier comparisons of the results in the multivariate analysis and support their reliability. The only exception is the number of sovereign bonds used for representing a country. S\&P has the highest number of 130 bonds whereas Moody's and Fitch are represented by 96 and 92 sovereign bonds respectively. This can be justified by the highest number of events being for S\&P. With cumulative two-day [0, +1] mean yield spread of 0.47 , S\&P has the lowest value for this variable. S\&P's conservatism could explain this phenomenon. According to Flynn and Ghent (2018), S\&P received the greatest regulatory pressure in the recent years. Descriptive statistics representing the variables used in the multivariate analysis are also reported in Table 2.

Furthermore, we construct a sample of non-events where each bond on the rating event date is matched with a randomly selected non-event date. ${ }^{10}$ The non-event sample comprises the same time period but includes only clean observations. These are defined as observations where no credit event for that sovereign, by any of the three CRAs, occurred in a window of 30 days before/after the non-event date. Additionally, there must be no rating change for the US by any of the three CRAs within 30 days before/after the non-event date. Finally, the nonevent date must not fall within the window of 30 days before/after the date of the introduction of identifier rules (30 April 2012). Additionally, when non-event and event observations are being matched in the pre- and post-identifier periods only, the clean observations from the relevant period are available for random selection. The total sample comprises 1646

\footnotetext{
${ }^{9}$ Despite its role in the European debt crisis, Greece does not feature in our sample because it did not issue any bonds denominated in US dollars which met our selection criteria.

${ }^{10}$ If the model was estimated using only event dates, relevant coefficients would be measuring the incremental change of rating action exceeding one CCR point in the yield spreads.
} 
observations with 692 for S\&P, 490 for Moody's and 464 for Fitch sub-samples respectively. ${ }^{11}$

\section{Multivariate analysis}

\subsection{Main methods}

In the empirical investigation, we focus solely on the impact of the introduction of regulation on the quality of sovereign ratings, not the interaction between changes in regulation and competition. Opp et al. (2013) argue that isolating the effect of changes in regulation is important. CRA competition plays a central role in rating quality of highly competitive non-sovereign rating markets. ${ }^{12}$ However, the role of competition is less intensive in our setting, given that the big three CRAs assign the vast majority of sovereign ratings.

Following the empirical literature (see Section 3), the quality of ratings is captured by the information content of ratings (Bae et al., 2015; Becker and Milbourn, 2011; Behr et al., 2018; Dimitrov et al., 2015). The quality is examined by testing whether the market is more aligned with ratings through bond yields before or after the cut-off date. When ratings accurately reflect issuers' creditworthiness and correlate strongly with bond yields, they reduce the information asymmetries between investors (and diminish risks for less-informed investors), which is indicative of high quality (Abad et al., 2019; Flynn and Ghent, 2018). On the other hand, any evidence of a weak correlation between bond yields and ratings suggests that ratings perform poorly in terms of information transmission (Becker and Milbourn, 2011). As suggested by Abad et al. (2019), low quality ratings harm the function of CRAs as information gatekeepers and make contracting with ratings more difficult.

\footnotetext{
${ }^{11}$ The non-event sample for each CRA contains the same number of observations as the event sample.

${ }^{12}$ For example, increased competition coincides with lower quality (inflated) ratings from incumbents in the corporate rating market (Dimitrov et al., 2015) and the structured finance rating market (Flynn and Ghent, 2018).
} 
If ESMA's aims are to be achieved, we hypothesize that the link between rating changes and bond yields should strengthen after the introduction of the identifier rules in April 2012. According to ESMA (2017b), ratings issued and endorsed in Europe fulfil the equivalence in methodology and transparency standards representing their high quality. Therefore, ratings should solely reflect factors related to the expected debt servicing by the issuer and correlate closely with the bond yields. In addition, this motivates an expectation that the location of rating analysts (in the EU or outside the EU) should not have a significant impact on the informativeness of sovereign ratings.

Because bond prices change far more frequently than ratings, we look at the change in informativeness (accuracy) levels rather than absolute match to market measures. Specifically, we test whether rating changes are able to explain bond yield changes (decreases or increases in bond spreads). This capability differentiates ratings into less or more informative. Separate sets of regressions for rating upgrades and downgrades are used due to their expected different outcomes, and for each of the three CRAs. We expect unequal effects across CRAs to be driven by differences in their methodologies, assumptions and performance (Bongaerts et al., 2012; Livingston et al., 2010). The baseline model examines our first research question regarding the impact of the identifiers disclosure rule on rating quality, as follows:

$$
\begin{aligned}
\Delta \text { Yield }_{i, t}=\beta_{1} \Delta \text { Rating }_{i, t} & +\beta_{2} \text { Identifier }_{i, t}+\beta_{3}\left(\Delta \text { Rating*Identifier }_{i, t}+\beta_{4} \text { Rating58 }_{i, t}\right. \\
& +\beta_{5} \text { Maturity }_{i, t}+\lambda_{1} \mathrm{CF}+\varepsilon_{i, t}
\end{aligned}
$$

$\Delta$ Yield $_{i, t}$ is the change in yield spread to the closest maturity US Treasury Bond for country $i$ on day $t$ in the time window $[0,+1]$, expressed in basis points.

$\triangle$ Rating is the change in sovereign issuer CCR by one of the three CRAs coded as absolute ordinal values 1 (1-CCR), 2 (2-CCR) and 3 (>2-CCR) for ease of interpretation, and 0 (no 
change). ${ }^{13}$ The coefficient $\beta_{1}$ resembles the marginal effect on yield spreads as a result of a unit change based on the CCR scale (on an event date and zero on a non-event date). Following Bae et al. (2015), Becker and Milbourn (2011) and Behr et al. (2018), we use the information content of ratings represented by linkages between rating actions and bond yields as a measure of rating quality. Positive rating actions should imply decreased risk for investors (i.e. narrower spreads), hence we expect a negative sign for the coefficient of $\Delta$ Rating. On the other hand, for the negative events, we expect a positive sign for the coefficient of $\Delta$ Rating, as the yield spreads should increase to reflect the underlying risk on the bonds.

The Identifier indicator variable equals 1 after the ESMA endorsement rules took effect on 30 April 2012, and 0 otherwise.

$\Delta$ Rating* Identifier, the key variable in this model, measures the linkage between quality of ratings and ESMA's requirement for identifiers by observing the impact of rating actions upon yields in the post-intervention period. The magnitude of rating events' impact on the bond spread in the post-identifier period is calculated by summation of the coefficient values of $\Delta$ Rating*Identifier and $\Delta$ Rating. In the case of positive rating changes, if the sign is negative (corresponding to the expected sign on the $\Delta$ Rating variable) and significant, positive rating events are informative as they are associated with narrowing bond yields in the post-identifier period. This corresponds to a high quality of ratings. On the other hand, if the interaction produces a positive significant coefficient, positive rating events widen (rather than narrow) bond yields in the post-identifier period, implying that ratings are of lower quality. Similarly, in the case of negative events, if the interaction has a positive significant coefficient, we detect stronger links between rating changes and spreads after the regulation was enacted, indicating a higher quality of ratings. Conversely, if the sign is negative, the

\footnotetext{
${ }^{13}$ We also estimate Eqs. (1), (2) and (3) using a binary variable that equals 1 on the day of a rating event and 0 otherwise. The results (available on request) are consistent.
} 
negative events are not informative as they narrow (rather than widen) spreads, suggesting lower quality of ratings.

Rating58 represents the sovereign's CCR taking values 1-58 and represents a proxy for the macroeconomic conditions of the sovereigns.

Maturity $_{i t}$ is the natural logarithm of the remaining years to maturity of the bond $i$ on the event date $t$. It controls for possible heterogeneity among spread changes which arise due to differences in the remaining years to maturity of bonds.

$C F$ is country fixed effects. ${ }^{14}$

To examine our second research question, on the impact of rating analysts' location on rating quality, Eq. (1b) is estimated to differentiate between the impact of rating events for issuers with EU versus EE identifiers in the post-identifier period in comparison with the impact of events in the pre-identifier period. Here, the null hypothesis suggests that ratings are of equivalent quality regardless of whether they are issued in the EU or elsewhere. Ratings should only reflect factors related to the expected debt servicing by the issuer, therefore we expect that the location of rating analysts (in the EU or outside the EU) has an insignificant impact on the informativeness of sovereign ratings. Superior quality of ratings issued by analysts located in the EU could be explained by the fact that the CRAs in the EU are under closer scrutiny in the post-identifier period. On the other hand, superior quality of endorsed ratings could stem from the fact that CRA offices in a non-EU country aim to establish a strong reputation for rating reliability. We test this using the following specification:

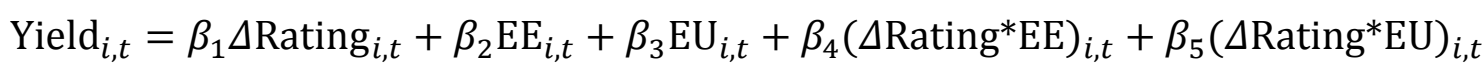

\footnotetext{
${ }^{14}$ We also estimate Eqs. (1), (2) and (3) including global time-varying risk factors (e.g. Acharya et al., 2013; Bedendo et al., 2018; Kahl et al., 2013). In separate estimations, we include one of three risk factors to explain the yield spreads: CBOE VIX volatility index, Treasury rate (5 years maturity), and interest rate swap spreads ( 5 years maturity). These results confirm the main findings.
} 


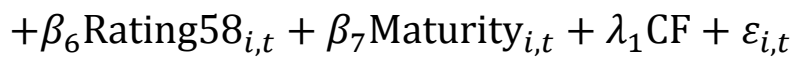

$E E(E U)$ takes the value of 1 if the rating of sovereign $i$ is EU endorsed (EU originated) in the post-identifier period (after 30 April 2012), 0 otherwise.

$\triangle$ Rating*EE/EU tests whether any change in rating quality depends on the location of the analyst. Here we are testing whether ratings originated outside the EU induce more (less) reaction in yield spreads than the ratings issued in the EU. For instance, if the interaction $\triangle$ Rating $* E E$, tested on the positive events sample, produces a negative significant coefficient, this implies a stronger link between bond yields and ratings in the post-identifier period when the rating is endorsed (rather than originated in the EU). If the sign is positive and significant, the effect between yields and ratings decreased, implying a lower quality of ratings in the post-identifier period when the ratings are assigned the EE identifier. The same logic applies to negative events, i.e. a positive and significant coefficient on the interaction term implies that sovereign rating actions assigned by analysts located outside the EU in the post-identifier period are of better quality. A negative sign would indicate a weaker link between the spreads and ratings in the post-identifier period for ratings issued in a jurisdiction outside the EU.

\subsection{Time versus cross-sectional variations}

In addressing our first research question regarding the impact of the identifiers disclosure rule, we conduct further investigations to ensure that some unobserved effects, which could be captured by the dummy variable Identifier, do not drive the results. We use two subsamples (i) pre-identifier period and (ii) post-identifier period, and compare the statistical significance of the variable $\Delta$ Rating in both periods. The following model is estimated:

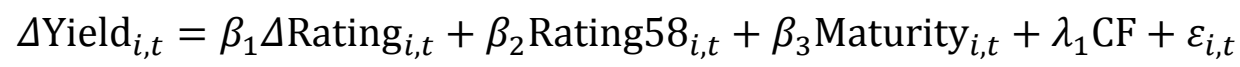


In Eq. (2), following Dimitrov et al. (2015), we examine the informativeness of rating news in two periods, before and after the identifiers disclosure rule. When interpreting the rating quality, we focus on both the size and significance of the coefficients. If the $\Delta$ Rating coefficient in the post-identifier period is statistically significant and with the expected sign (negative for positive events and positive for negative events) and larger in magnitude than the $\Delta$ Rating coefficient in the pre-identifier period, we conclude that the rating news is of better quality (i.e. more informative) in the post-identifier period. On the other hand, if the $\Delta$ Rating coefficient in the post-identifier is insignificant or significant with either the opposite sign or with the expected sign but with smaller magnitude, then we conclude that ratings news in the post-identifier period is of lower quality (i.e. less informative).

We further conduct an F-test to compare the coefficients on the $\Delta$ Rating variable in the pre- and post-identifier periods. ${ }^{15}$ This tests the hypothesis that the beta coefficient of $\Delta$ Rating in the pre-identifier sample $\left(\beta_{1}(\mathrm{i})\right)$ is equal to the beta coefficient of $\Delta$ Rating in the post-identifier period $\left(\beta_{1}\right.$ (ii)). Positive and negative events are tested separately for each of the three CRAs. If the new identifiers deliver better rating quality, then absolute values of $\beta_{1}$ (in sample (i) will be smaller than $\beta_{1}$ in sample (ii), because rating changes better explain the bond yields after the rule was introduced. On the other hand, if the regulation has a weak effect (poorer rating quality), then absolute values of $\beta_{1}$ in sample (i) will be greater than $\beta_{1}$ in sample (ii).

To further investigate our second research question, ruling out any other events coinciding with the adoption of the endorsement rules, we disentangle the possible effect that an analyst's location might have on the quality of ratings (via the use of identifiers). We estimate Eq. (2) using only the post-identifier period (May 2012-June 2016) with the distinction between ratings issued in the EU versus ratings issued in EU-endorsed countries (EE

\footnotetext{
15 The test is performed using seemingly unrelated regression, which estimates the simultaneous (co)variance of the coefficients of the two equations being compared.
} 
identifier). Then, we compare the magnitude of the coefficient of $\Delta$ Rating in the two subsamples (EE versus EU sub-samples) and test the statistical difference between them. The EU (EE) sub-sample consists of sovereign rating events for issuers with EU (EE) identifiers. The null hypothesis states that ratings issued by analysts in the EU and in the EU-endorsed countries in the post-identifier period are of equal quality. If the EU issued ratings are of higher quality, we expect the absolute values of $\beta_{1}$ (ii) for the EU sub-sample to be greater than $\beta_{1}$ (ii) in the EE sub-sample, because rating changes are better at explaining bond yields when analysts are based in Europe. Superior quality of ratings from analysts within the EU could be explained by the fact that the EU has high levels of stringency in regulations and the actions of CRAs are directly supervised and overseen by ESMA. Conversely, if EU endorsed ratings are of better quality, we would expect the absolute values of $\beta_{1}$ (ii) for the EE subsample to be greater than $\beta_{1}$ (ii) in the EU sub-sample because there is greater effect of the rating news on the spread in the endorsed countries. Superiority of ratings assigned outside the EU could stem from the fact that for these ratings to be endorsed, the actions of the third country CRAs issuing them need to be overseen by the endorsing CRA rather than ESMA. The third country's CRAs have strong incentives to signal quality and reliability of their ratings to maintain their reputation in the EU system and with ESMA.

In addition, we further investigate our second research question regarding the impact of the rating analysts' location, ensuring that no other events (time nor cross-section related) coincided with the adoption of the disclosure rules. We apply the quasi-experimental design of difference-in-differences estimation, where we focus on the differences arising between the treatment and control groups, as follows:

$$
\begin{aligned}
& \Delta \text { Yield }_{i, t}=\beta_{1}\left(\Delta \text { Rating }^{*} \mathrm{EEB}\right)_{i, t}+\beta_{2}\left(\Delta \text { Rating }^{*} \mathrm{EUB}\right)_{i, t}+\beta_{3}\left(\Delta \text { Rating }^{*} \mathrm{EE}\right)_{i, t}+
\end{aligned}
$$

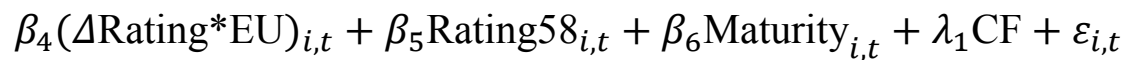


$E E B$ (' $E E$ ' Before) is equal to 1 during the pre-disclosure period for ratings which have the 'EE' identifier in the post-disclosure period, and 0 otherwise. EUB ('EU' Before) is equal to 1 during the pre-disclosure period for ratings which have the 'EU' identifier in the postdisclosure period, and 0 otherwise. 'EE' and 'EU' are defined as in Eq. (1b). We assume that the EU jurisdiction is constant (control group), while the treatment group is the endorsed group of ratings following from the regulatory action (EE identifiers). We assume that ratings which have 'EU' identifiers in the post-disclosure period already had ratings issued within the EU in the pre-disclosure period. In the difference-in-differences terminology, these ratings are not 'treated' upon implementation of the identifiers regulation, hence they act as a control group. It is then assumed that ratings which have 'EE' identifiers in the postdisclosure period were issued outside the EU in the pre-disclosure period. Upon implementation of the identifiers regulation, these ratings are 'treated' i.e. become subject to endorsement by the EU. In this test, we investigate whether the location of rating analyst affected sovereigns (EU originated vs EU endorsed) from both groups to a different extent. Specifically, we examine whether EU originated ratings captured via $\Delta R a t i n g * E U$ are of higher or lower quality than the EU endorsed ratings captured by $\triangle$ Rating*EE. We consider rating events of higher quality if the interaction is negative (positive) and significant for positive (negative) events, and vice versa.

\section{Empirical results}

\subsection{Main estimation results}

Table 3 presents the results of Eq. (1a), which examines the first research question, and Eq. (1b), which examines the second research question, by each CRA for positive events in Panel I and negative events in Panel II. The coefficient on $\Delta$ Rating is significant with the expected sign for S\&P and Moody's positive events and for S\&P and Fitch negative events. 
This indicates a strong overall link between ratings and bond spreads during the pre-identifier period. As expected, the effect of the identifier on the quality of ratings reveals varying results across CRAs. Differing market impact by ratings from different CRAs has been found in prior literature (e.g. Arezki et al., 2011; Bongaerts et al., 2012: Livingston et al., 2010) and relates to the fact that CRAs use different methodologies and assumptions (e.g. Afonso et al., 2012; Flynn and Ghent, 2018). Additionally, CRAs apply different weights on different factors in their rating processes. These differences often lead to differences (in sovereign ratings) across CRAs. ${ }^{16}$ The frequency of differences in CRA opinion (split ratings) for sovereign debt has increased significantly during and after the global financial crisis. Split sovereign ratings for advanced economies are now as common as they once were for emerging economies (Amstad and Packer, 2015).

Several papers report asymmetric reactions of bond yields and stock market returns to negative versus positive rating actions (e.g. Abad et al., 2019; Baum et al., 2016; Kisgen and Strahan, 2010). It is argued that rating downgrades provide a greater surprise element in comparison to rating upgrades (e.g. Gande and Parsley, 2005; Hill et al., 2018). CRAs might be less inclined to issue downgrades to sovereigns in fear of losing business within other assets classes in that country (Gande and Parsley, 2005). In addition, CRAs may face higher penalties for overstating rather understating the creditworthiness of issuers (Goel and Thakor, 2011), and therefore have stronger incentives to issue more conservative rather than more generous ratings in order to protect their reputation (Baghai et al., 2014; Bannier et al., 2010).

Regarding our first research question (using Eq. (1a)), Panel I of Table 3 shows poorer rating quality (less informative ratings) for positive events by all CRAs in the post-identifier period (refer to the interaction term). Conversely, better quality ratings (more informative

\footnotetext{
${ }^{16}$ Previous literature has found that S\&P tends to be the most conservative amongst CRAs and its downgrades have stronger effects than those of other CRAs (e.g Flynn and Ghent, 2018). Earlier research has also shown that S\&P places more weight on rating accuracy whereas Moody's has a greater emphasis on rating stability (e.g. Cheng and Neamtiu, 2009; Kiff et al., 2012).
} 
ratings) are reported in Panel II for Moody's negative events. Regarding our second research question (Eq. (1b)), we observe less informative positive events when S\&P's rating analysts are located in the EU, and when rating analysts of Moody's and Fitch are based outside the EU. In addition, Fitch negative events are more informative when their rating analysts are based outside the EU (i.e. ratings with EE identifiers).

The coefficient on $\Delta$ Rating (Eq. (1a) in Panel I suggests that bond spreads narrow by $10.26(3.420 * 3)$ basis points on average after S\&P issues an upgrade by one notch (3-CCR points), implying a strong link between ratings and bond spreads in the pre-identifier period. The coefficient on $\Delta$ Rating*Identifier is positive and significant in the results of Eq. (1a), implying a poorer rating quality of $\mathrm{S} \& \mathrm{P}$ upgrades in the post-identifier period. The magnitude of rating events' impact on the bond spread in the post-identifier period is calculated as the sum of the coefficient on $\Delta$ Rating*Identifier and the coefficient on $\Delta$ Rating. On average, bond spreads widen (rather than narrow) by 0.672 basis points $[(-3.420+3.644) * 3]$ after S\&P issues an upgrade by one-notch (3-CCR points) after the disclosure rule. In addition, the coefficient on $\triangle$ Rating $* E U$ (in Eq. (1b) in Panel I) is positive and significant, implying that S\&P's positive events are less informative when their analysts are located in EU countries. The results in Panel II, Eq. (1a), suggest that a one notch downgrade by S\&P leads to an increase in bond yield spreads by $11.78(3.926 * 3)$ basis points on average.

For Moody's positive rating events (see Panel I of Table 3), the results reveal a strong link between ratings and the bond spreads. For instance, in Eq. (1a), an upgrade of one notch by Moody's leads to a narrowing bond spread by $9.678(3.226 * 3)$ basis points. The results also indicate poorer quality of positive events by Moody’s (similar to S\&P positive events) after the introduction of the disclosure rule. This is evident from the positive and significant coefficient on the interaction term (ARating*Identifier) in Eq. (1a), suggesting that, on average, bond spreads widen by $0.507[(-3.226+3.395) * 3]$ basis points after Moody's issues 
an upgrade by one-notch (3-CCR points) after the disclosure rule. Additionally, the results of Eq. (1b) suggest that Moody's positive events are less informative when their rating analysts are located outside the EU (i.e. ratings with EE identifiers). Although the market reaction to Moody's negative events is insignificant in the pre-identifier period (insignificant coefficient on $\Delta$ Rating), their information content increases in the post-identifier period because the coefficient on $\Delta$ Rating*Identifier in Eq. (1a) is positive and significant (Panel II). The coefficient signifies that bond spreads widen by $14.775[(-2.039+6.964) * 3]$ basis points on average as a result of a rating downgrade by one notch by Moody's.

The market reactions to Fitch's positive events are insignificant in the pre-identifier period (insignificant coefficient on $\Delta$ Rating), and their information content deteriorates in the post-identifier period because the coefficient on $\Delta$ Rating*Identifier is positive and significant (in Eq (1a), Panel I). The coefficient signifies that the bond spreads widen (rather than narrow) by $2.445[(-1.399+2.214) * 3]$ basis points on average as a result of a one-notch rating upgrade by Fitch. The results of Eq. (1b) in Panel I reveal that Fitch positive events are less informative when their analysts are located outside the EU (ratings with EE identifiers) in the post-identifier period. Panel II of Table 3 shows that the average bond spread increases by $8.31(2.770 * 3)$ basis points following a one-notch downgrade by Fitch (Eq. (1a)) in the pre-identifier period. The positive and significant coefficient on $\triangle$ Rating ${ }^{*} E E$ (Eq. (1b), Panel II) suggests that the effect of Fitch negative events on yields in the post-identifier period is stronger, thus indicating higher quality, when their rating analysts are located outside the EU (i.e. ratings with EE identifiers).

\subsection{Time versus cross-sectional variations}

Tables 4-6 present the results of Eq. (2), which examines our first research question on the impact of rating identifiers, tested using (i) pre-identifier and (ii) and post-identifier data 
samples. This robustness exercise allows us to observe the quality of ratings measured by their information content during the pre- and post-identifier periods (similar to Dimitrov et al., 2015). A significant (insignificant) coefficient on $\Delta$ Rating implies high (poor) quality ratings in a given period because we are able to observe the extent to which bond yields respond to rating news (Becker and Milbourn, 2011). F-test results reveal statistical differences between the $\Delta$ Rating coefficients in the pre- and post-identifier sample periods for all estimations. The results of Tables 4-6 largely confirm the results from Eq. (1a). Specifically, there is a deterioration in rating quality associated with positive news from all CRAs after the disclosure rule, while better quality ratings (more informative ratings) for Moody's negative events. In addition, there is some evidence that Fitch (S\&P) negative events are more (less) informative, i.e. better (lower) rating quality, in the post-identifier than in the pre-identifier period.

For S\&P positive and negative events (Table 4), the coefficient on $\Delta$ Rating is significant, with the expected sign, in the pre-identifier period only and of much greater magnitude than in the post-identifier period $\left(-3.408^{* *}\right.$ vs. 0.253 for positive events; $4.174 * *$ vs. 1.169 for negative events). The F-test confirms that the $\Delta$ Rating coefficient is statistically different across the two sub-periods (Prob>Chi-squared $=0.038$ for positive events and 0.058 for negative events). These imply that S\&P positive and negative events are less informative (lower quality) in the post-identifier versus pre-identifier period.

For Moody's positive events (Table 5), similarly to those of S\&P, the coefficient on $\Delta$ Rating is significant with the expected negative sign in the pre-identifier period only, and its coefficient's magnitude is larger than in the post-identifier period $(-3.474 * * *$ vs. -0.315$)$. The F-test confirms that rating quality differs in the periods before and after the disclosure rule (Prob> Chi-squared $=0.052$ ). This indicates that Moody's positive events are less informative (lower quality) in the post-identifier than in the pre-identifier period, which is 
consistent with the relevant result in Table 3 (Eq. (1a)). For Moody's negative events, $\Delta$ Rating is significant only in the post-identifier period, with the F-test confirming different rating quality between these periods. This implies that Moody's negative events are more informative (of better quality) in the post-identifier than pre-identifier period, which is again consistent with the result of Table 3 (Eq. 1a).

For Fitch positive events, the coefficient on $\Delta$ Rating is significant in both time periods, with an unexpected positive sign in the post-identifier period, suggesting lower quality of Fitch positive events in the post-identifier period (in line with the relevant results in Table 3 (Eq. (1a)). For Fitch negative events, the coefficient on $\Delta$ Rating is only significant in the post- regulatory period with expected positive sign (i.e. wider spread). This indicates some evidence that Fitch negative events are more informative (better quality) in the post-identifier than in the pre-identifier period. The F-test results in Table 6 confirm that rating quality differs in the periods before and after the disclosure rule (Prob> Chi-squared $=0.002$ for positive events and 0.061 for negative events).

To further examine the second research question regarding the impact of rating analysts' location on rating quality, we also estimate Eq. (2) using a sub-sample for the post-identifier period for the two groups of countries (EU-originated and EU-endorsed ratings) with the results presented in Tables 7-9. The results for news from S\&P (Table 7) and Moody's (Table 8) are inconsistent with those of Eq. (1b) in Table 3. The coefficient on $\Delta$ Rating is insignificant for $\mathrm{S} \& \mathrm{P}$ positive events, and with an insignificant F-test result, thereby suggesting that the location of $\mathrm{S} \& \mathrm{P}$ analysts (inside or outside the EU) has no significant impact on the information content of its positive events. A positive and significant (at the $10 \%$ level) coefficient on $\Delta$ Rating for S\&P negative events is reported for the EE sub-sample, suggesting that this type of news is more informative when S\&P analysts are located outside the EU. In Table 8, Moody's positive events are more informative when their rating analysts 
are located in the EU (the coefficient on $\Delta$ Rating has the expected negative sign and is significant at the $10 \%$ level). ${ }^{17}$

On the other hand, the coefficient on $\Delta$ Rating is significant (with an unexpected positive sign) for Fitch positive events for ratings with EE identifiers (Table 9). This is consistent with the findings of Eq. (1b), indicating that these rating events are less informative, and is supported by a highly significant F-test result. The magnitude of the $\Delta$ Rating coefficient for Fitch negative events suggests that they have a stronger impact on widening bond spreads when Fitch's rating analysts are located outside the EU (i.e. ratings with EE identifiers), and thus are of better quality than ratings issued by analysts located in the EU $(6.092 * * *$ for EE versus $2.114^{*}$ for EU). The F-test result confirms that rating quality differs between these EE- and EU- sub-samples (Prob> Chi-squared $=0.096)$.

We further investigate our second research question, regarding the impact of the rating analysts' location, by applying the difference-in-differences estimation of Eq. (3). The results, reported in Table 10, support the earlier findings based on Eq. (1b). Positive events by S\&P and Moody's are less informative (lower quality) in the post-identifier period when S\&P rating analysts are located inside the EU and when Moody's rating analysts are located outside the EU. This effect is captured by positive and significant coefficients (implying wider spreads) on $\Delta$ Rating*EU and $\Delta$ Rating*EE variables respectively. However, for Fitch, the relevant results in Table 10 are insignificant and do not support those of Table 3 (Eq. (1b)) and Table 9 (Eq. (2)) which suggest that Fitch positive (negative) events are less (more) informative when Fitch rating analysts are located outside the EU.

\footnotetext{
${ }^{17}$ There are only 7 negative events by Moody's in the EU sub-sample in the post-identifier period. The results in this case are not reliable and we have not reported the F-test.
} 


\section{Conclusions}

This paper presents a unique analysis of the impact of EU endorsement rules on the quality of credit ratings. Using a rich dataset of sovereign rating actions from Fitch, Moody's and S\&P for 70 countries during the period of 2006-2016, this paper presents the first evidence on the influence of ESMA identifiers. We investigate whether rating quality has changed as a consequence of the new disclosures, by utilizing the link between rating actions and bond yields. We also examine whether the location of rating analysts, inside versus outside the EU (i.e. ratings with $\mathrm{EU}$ versus $\mathrm{EE}$ identifiers), has a significant impact on rating informativeness. One key aspect in which this paper differs from studies based on US regulation is that it investigates the direct effect of the disclosure rules on rating quality, rather than measuring the effect of changing competition amongst CRAs.

Our results suggest that the use of endorsement via identifiers does not achieve its objective of improved rating quality. In fact, there are cases of significant decreases in quality after the disclosure rules were introduced. Poorer (less informative) rating actions are reported for positive events by all CRAs after the introduction date. More detailed tests reveal some limited evidence that Moody's and Fitch rating actions are less informative when the analysts are based outside the EU. Such inferior rating quality might be a consequence of third country CRA offices facing less scrutiny than those in the EU. In contrast, less informative positive events by S\&P are those with EU identifiers. These findings are consistent with Dimitrov et al. (2015) who report that the US Dodd-Frank Act did not result in more accurate nor more informative ratings. To some extent, our results also resonate with Behr et al.'s (2018) findings that the US CRA regulation (SEC certification) had an adverse effect on quality as revealed via ratings inflation.

On the other hand, we find evidence of improvements in information content in the cases of Moody's negative rating actions. Additionally, better quality rating downgrade actions are 
associated with Fitch when their rating analysts are located outside the EU (i.e. with 'EE' categories). Third country CRA offices seeking to establish a strong reputation for rating quality might explain this outcome. This is in line with the improved accuracy of downgrades reported by Bedendo et al. (2018) and de Haan (2017) for corporate ratings.

ESMA's identifiers are intended to improve rating quality, yet not to be affected by the location of ratings analysts. Our mixed evidence on the impact of rating analysts' location on rating informativeness clearly contributes towards an important stream of literature which assesses the effects of regulation on the quality of ratings. There has been no prior evidence on this aspect in the context of European CRA regulation. Yet, it deserves further attention from both regulators and academic researchers. Further, our findings of differing impact across different CRAs and rating events are consistent with the findings of prior literature with regard to the varying impact of positive versus negative sovereign rating news on financial markets (e.g. Afonso et al., 2012; Baum et al., 2016; Bedendo et al., 2018).

Our findings are broadly in line with the theoretical predictions of Opp et al. (2013). These authors suggest that the quality of ratings as revealed by information content might improve or deteriorate depending on whether there are regulatory gains for the CRA from collecting additional information. If the costs of acquiring additional information outweigh its benefits, CRAs might decide to inflate ratings instead (e.g., our findings on all CRAs' positive events). They also argue that when regulation promotes highly rated securities, the information content of rating actions (rating quality) may change depending on an endogenous threshold level of regulatory advantage. When the threshold has been crossed, the CRA no longer acquires information and enables regulatory arbitrage by inflating its ratings. Our results support the underlying premise of this theory. On the one hand, lower quality of upgrades by CRAs might suggest that the regulatory advantage of obtaining more information to issue such revisions is outweighed by the costs, and CRAs prefer to inflate the ratings instead. On 
the other hand, since some negative events signal new and unanticipated information to the market and result in stronger market reactions, CRAs may be encouraged by the regulation to invest time and resources in ensuring the quality of rating downgrades.

ESMA's endorsement rules and the introduction of identifiers are very specific regulatory initiatives and cannot be directly compared to any regulations introduced in the US nor to any prior empirical studies. Investigating the influence of these endorsement rules on financial markets is of importance to policymakers, governments and market participants alike. Endorsement and identifiers could add credibility to CRAs' decisions, thereby increasing the influence of rating actions. This paper's findings thereby make a unique contribution to the policy debate. 


\section{References}

Abad, P., Ferreras, R., Robles, M-D., 2019. Informational role of rating revisions after reputational events and regulation reforms. International Review of Financial Analysis 62, 91-103.

Acharya, V., Almeida, H., Campello, M., 2013. Aggregate risk and the choice between cash and lines of credit. Journal of Finance 68, 2059-2116.

Afonso, A., Furceri, D., Gomes, P., 2012. Sovereign credit ratings and financial markets linkages: Application to European data. Journal of International Money and Finance 31, 606-638.

Almeida, H., Ferreira, M.A., Restrepo, F., 2017. The real effects of credit ratings: the sovereign ceiling channel. Journal of Finance 72, 249-290.

Amstad, M., Packer, F., 2015. Sovereign ratings of advanced and emerging economies after the crisis. BIS Quarterly Review, December 2015.

Arezki, R., Candelon, B., Sy, A., 2011. Sovereign rating news and financial markets spillovers: Evidence from the European debt crisis. International Monetary Fund (IMF), Working Paper No. 11/68, pp. 1-27.

Bae, K.H., Kang, J.K., Wang, J., 2015. Does increased competition affect credit ratings? A re-examination of the effect of Fitch's market share on credit ratings in the corporate bond market. Journal of Financial and Quantitative Analysis 50, 1011-1035.

Baghai, R. P., Servaes, H., Tamayo, A., 2014. Have rating agencies become more conservative? Implications for capital structure and debt pricing. Journal of Finance 69, 1961-2005.

Bank for International Settlements (BIS) 2017. Basel III: Finalising post-crisis reforms. December 2017.

Bank for International Settlements (BIS) 2014. Revisions to the Standardised Approach for credit risk. Basel Committee on Banking Supervision (BCBS) Consultative Document. December 2014.

Bannier, C., Behr. P., Güttler, A., 2010. Rating opaque borrowers: Why are unsolicited ratings lower? Review of Finance 2, 263-294.

Baum, C.F., Schafer, D., Stephan, A., 2016. Credit rating agency downgrades and the Eurozone sovereign debt crises. Journal of Financial Stability 24, 117-131.

Becker, B., Milbourn, T., 2011. How did increased competition affect credit ratings? Journal of Financial Economics 101, 493-514.

Bedendo, M., Cathcart, L., El-Jahel. L., 2018. Reputational shocks and the information content of credit ratings. Journal of Financial Stability 34, 44-60. 
Behr, P., Kisgen, D., Taillard, J., 2018. Did government regulations lead to inflated credit ratings? Management Science 64, 1034-1054.

Bolton, P., Freixas, X., Shapiro, J., 2012. The credit ratings game. Journal of Finance 67, 85112.

Bongaerts, D., Cremers, M., Goetzmann, W., 2012. Tiebreaker: Certification and multiple credit ratings. Journal of Finance 67, 113-152.

Borensztein, E., Cowan, K., Valenzuela, P., 2013. Sovereign ceiling lite? The impact of sovereign ratings on corporate ratings in emerging market economies. Journal of Banking and Finance 37, 4014-4024.

Cai, P., Kim, S., Wu, E., 2019. Foreign direct investments from emerging markets: The pushpull effects of sovereign credit ratings. International Review of Financial Analysis 61, 110-125.

Chen, S., Chen, H., Chang, C., Yang, S., 2016. The relation between sovereign credit rating revisions and economic growth. Journal of Banking and Finance 64, 90-100.

Cheng, M., Neamtiu, M., 2009. An empirical analysis of changes in credit rating properties: Timeliness, accuracy and volatility. Journal of Accounting and Economics 47, 108-130.

De Haan, E., 2017. The financial crisis and corporate credit ratings. The Accounting Review 92, 161-189.

Dimitrov, V., Palia, D., Tang, L., 2015. Impact of the Dodd-Frank Act on credit ratings. Journal of Financial Economics 115, 505-520.

Dodd-Frank Act 936, 2010. SEC. Qualification standards for credit rating analysts.

Doherty, N., Kartasheva, A., Phillips, R., 2012. Information effect of entry into credit ratings market: The case of insurers' ratings. Journal of Financial Economics 106, 308-330.

European Central Bank (ECB) 2012. Opinion of the European Central Bank of 2 April 2012. Official Journal of the European Union 167C, 2-14.

European Commission (EC) 2011. Proposal for a regulation of the European Parliament and of the Council amending Regulation (EC) No 1060/2009 on credit rating agencies. November 2011.

European Securities and Markets Authority (ESMA) 2017a. ESMA clarifies endorsement regime for third-country credit ratings. Press Release. November 172017. ESMA71/99/642.

European Securities and Markets Authority (ESMA) 2017b. Update of the guidelines on the application of the endorsement regime under Article 4(3) of the Credit Rating Agencies Regulation. Final Report. November 17 2017. ESMA33/9/205.

European Securities and Markets Authority (ESMA) 2017c. Final Report Technical advice on CRA regulatory equivalence - CRA 3 update. November 17 2017. ESMA33/9/207. 
European Securities and Markets Authority (ESMA) 2016. Competition and choice in the credit rating industry. Market share calculation required by Article 8d of Regulation 1060/2009 on Credit Rating Agencies as amended. December 16 2016. ESMA/2016/1662.

European Securities and Markets Authority (ESMA) 2012. ESMA approves credit ratings from Brazil for use in the EU. Press Release. April 27 2012. ESMA/2012/274.

European Securities and Markets Authority (ESMA) 2011a. Guidelines on the application of the endorsement regime under Article 4(3) of the Credit Rating Regulation 1060/2009. ESMA/2011/139.

European Securities and Markets Authority (ESMA) 2011b. ESMA allows EU-registered CRAs to endorse credit ratings issued in the US, Canada, Hong Kong and Singapore. Press Release. ESMA/2012/158.

Flynn, S., Ghent, A., 2018. Competition and credit ratings after the fall. Management Science 64, 1672-1692.

Gande, A., Parsley, D.C., 2005. News spillovers in the sovereign debt market. Journal of Financial Economics 73, 691-734.

Goel, A., Thakor, A., 2011. Credit ratings and litigation risk. Working paper. Navigant Economics and Washington University, Saint Louis.

Hill, P., Bissoondoyal-Bheenick, E., Faff, R., 2018. New evidence on sovereign to corporate credit rating spill-overs. International Review of Financial Analysis 55, 209-225.

Kahl, M., Shivdasani, A., Yihui, W., 2015. Short-term debt as bridge financing: Evidence from the commercial paper market. Journal of Finance 70, 211-255.

Kiff, J., Nowak, S., Schumacher, L., 2012. Are rating agencies powerful? An investigation into the impact and accuracy of sovereign ratings. International Monetary Fund working paper, WP/12/23.

Kisgen, D.J., Strahan, P.E., 2010. Do regulations based on credit ratings affect a firm's cost of capital? Review of Financial Studies 23, 4324-4347.

Livingston, M., Wei, D., Zhou, L., 2010. Moody's and S\&P ratings: Are they equivalent? Conservative ratings and split rated bond yields. Journal of Money, Credit and Banking 42, 1267-1293.

Official Journal of the European Union (OJEU) 2013. Regulation (EU) No 462/2013 of the European Parliament and of the Council of 21 May 2013 amending Regulation (EC) No 1060/2009 on credit rating agencies. Regulation Legislative Acts 146/1, 31 May 2013.

Opp, C.C., Opp, M.M., Harris, M., 2013. Rating agencies in the face of regulation. Journal of Financial Economics 108, 46-61. 
Table 1. Sovereign credit rating actions by CRAs

\begin{tabular}{|c|c|c|c|c|c|c|}
\hline Entire sample & \multicolumn{2}{|c|}{ S\&P } & \multicolumn{2}{|c|}{ Moody's } & \multicolumn{2}{|c|}{ Fitch } \\
\hline Observations & 346 & & 245 & & 232 & \\
\hline Average numerical rating & 27.41 & & 28.13 & & 29.07 & \\
\hline Positive events & 152 & $43.93 \%$ & 141 & $57.55 \%$ & 116 & $50.00 \%$ \\
\hline Upgrade by $1 \mathrm{CCR}$ point & 77 & $22.25 \%$ & 74 & $30.20 \%$ & 52 & $22.42 \%$ \\
\hline Upgrade by 2 CCR point & 36 & $10.41 \%$ & 41 & $16.73 \%$ & 35 & $15.08 \%$ \\
\hline Upgrade by > 2 CCR point & 39 & $11.27 \%$ & 26 & $10.61 \%$ & 29 & $12.50 \%$ \\
\hline Negative events & 194 & $56.07 \%$ & 104 & $42.45 \%$ & 116 & $50.00 \%$ \\
\hline Downgrade by 1 CCR point & 94 & $27.17 \%$ & 47 & $19.18 \%$ & 57 & $24.57 \%$ \\
\hline Downgrade by 2 CCR point & 43 & $12.43 \%$ & 35 & $14.29 \%$ & 22 & $9.48 \%$ \\
\hline Downgrade by $>2 \mathrm{CCR}$ point & 57 & $16.47 \%$ & 22 & $8.98 \%$ & 37 & $15.95 \%$ \\
\hline Total no of events & 346 & $100.00 \%$ & 245 & $100.00 \%$ & 232 & $100.00 \%$ \\
\hline \multicolumn{7}{|l|}{ Pre-identifier } \\
\hline Observations & 181 & & 121 & & 124 & \\
\hline Average numerical rating & 28.27 & & 29.92 & & 30.37 & \\
\hline Positive events & 83 & $45.86 \%$ & 81 & $66.94 \%$ & 64 & $51.61 \%$ \\
\hline Upgrade by $1 \mathrm{CCR}$ point & 40 & $22.10 \%$ & 47 & $38.84 \%$ & 29 & $23.39 \%$ \\
\hline Upgrade by 2 CCR point & 18 & $9.95 \%$ & 24 & $19.84 \%$ & 21 & $16.93 \%$ \\
\hline Upgrade by $>2$ CCR point & 25 & $13.81 \%$ & 10 & $8.26 \%$ & 14 & $11.29 \%$ \\
\hline Negative events & 98 & $54.14 \%$ & 40 & $33.06 \%$ & 60 & $48.39 \%$ \\
\hline Downgrade by $1 \mathrm{CCR}$ point & 45 & $24.86 \%$ & 22 & $18.18 \%$ & 31 & $25.00 \%$ \\
\hline Downgrade by $2 \mathrm{CCR}$ point & 22 & $12.15 \%$ & 18 & $14.88 \%$ & 10 & $8.06 \%$ \\
\hline Downgrade by $>2 \mathrm{CCR}$ point & & $17.13 \%$ & 0 & $0.00 \%$ & 19 & $15.32 \%$ \\
\hline Total no of events & 181 & $100.00 \%$ & 121 & $100.00 \%$ & 124 & $100.00 \%$ \\
\hline \multicolumn{7}{|l|}{ Post-identifier } \\
\hline Observations & 165 & & 124 & & 108 & \\
\hline Average numerical rating & 2 & & 26.38 & & 27.58 & \\
\hline Positive events & 69 & $41.82 \%$ & 60 & $48.39 \%$ & 52 & $48.15 \%$ \\
\hline Upgrade by 1 CCR point & 37 & $22.42 \%$ & 27 & $21.77 \%$ & 23 & $21.30 \%$ \\
\hline Upgrade by 2 CCR point & 18 & $10.91 \%$ & 17 & $13.71 \%$ & 14 & $12.96 \%$ \\
\hline Upgrade by > 2 CCR point & 14 & $8.48 \%$ & 16 & $12.90 \%$ & 15 & $13.89 \%$ \\
\hline Negative events & 96 & $58.18 \%$ & 64 & $51.61 \%$ & 56 & $51.85 \%$ \\
\hline Downgrade by $1 \mathrm{CCR}$ point & 49 & $29.70 \%$ & 25 & $20.16 \%$ & 26 & $24.07 \%$ \\
\hline Downgrade by 2 CCR point & 21 & $12.72 \%$ & 17 & $13.71 \%$ & 12 & $11.11 \%$ \\
\hline Downgrade by $>2 \mathrm{CCR}$ point & 26 & $15.76 \%$ & 22 & $17.74 \%$ & 18 & $16.67 \%$ \\
\hline Total no of events & 165 & $100.00 \%$ & 124 & $100.00 \%$ & 108 & $100.00 \%$ \\
\hline
\end{tabular}

Note: This table presents summary statistics for the credit rating dataset, which includes daily sovereign rating observations including outlook and watch by S\&P, Moody's and Fitch for 70 countries for pre-identifier (Jan 2006-April 2012) and post-identifier (May 2012-June 2016) periods. 
Table 2. Summary statistics of credit events by CRAs

\begin{tabular}{lrrr}
\hline Sample & S\&P & Moody's & Fitch \\
\hline No of countries & 66 & 54 & 51 \\
No of sovereign bonds & 130 & 96 & 92 \\
No of benchmark bonds & 65 & 56 & 52 \\
Mean $\Delta$ Yield & 0.47 & 1.68 & 2.22 \\
S.D. $\Delta$ Yield & 23.14 & 23.36 & 16.70 \\
Mean Rating58 (1-58) & 27.41 & 28.13 & 29.07 \\
S.D. Rating58 (1-58) & 12.06 & 12.47 & 11.58 \\
Mean term to maturity (years) & 7.39 & 6.79 & 6.98 \\
S.D. term to maturity (years) & 6.49 & 6.20 & 5.99 \\
Mean coupon rate (\%) & 6.82 & 6.98 & 6.78 \\
S.D. coupon rate (\%) & 2.30 & 2.33 & 2.25 \\
Mean amount issued (billion USD) & 1.19 & 1.13 & 1.23 \\
S.D. amount issued (billion USD) & 1.07 & 1.04 & 1.05 \\
\hline
\end{tabular}

Notes. This table presents summary statistics of credit events for each CRA for 70 sovereigns from Jan 2006 to June 2016. YYield is the change in yield spread to the closest maturity Treasury Bond in the time window $[0,+1]$. Rating 58 represents sovereign's CCR taking values 1-58. Maturity is bond's time to maturity. 
Table 3. Impact of identifiers on the quality of ratings as measured by bond yields

Panel I: Positive events

\begin{tabular}{|c|c|c|c|c|c|c|}
\hline \multirow[b]{2}{*}{ VARIABLES } & \multicolumn{2}{|c|}{$\mathbf{S \& P}$} & \multicolumn{2}{|c|}{ Moody's } & \multicolumn{2}{|c|}{ Fitch } \\
\hline & Eq.(1a) & Eq.(1b) & Eq.(1a) & Eq.(1b) & Eq.(1a) & Eq.(1b) \\
\hline$\Delta$ Rating & $\begin{array}{c}-3.420 * * * \\
(-2.86)\end{array}$ & $\begin{array}{c}-3.476 * * * \\
(-2.87)\end{array}$ & $\begin{array}{c}-3.226 * * \\
(-2.20)\end{array}$ & $\begin{array}{c}-3.232 * * \\
(-2.20)\end{array}$ & & $\begin{array}{l}-1.401 \\
(-1.55)\end{array}$ \\
\hline Identifier & $\begin{array}{l}-1.674 \\
(-0.54)\end{array}$ & & $\begin{array}{l}-1.894 \\
(-0.54)\end{array}$ & & $\begin{array}{l}-4.636 \\
(-0.92)\end{array}$ & \\
\hline$\Delta$ Rating* Identifier & $\begin{array}{c}3.644 * * \\
(1.99)\end{array}$ & & $\begin{array}{c}3.395^{*} \\
(1.65)\end{array}$ & & $\begin{array}{l}2.214^{*} \\
(1.67)\end{array}$ & \\
\hline Rating58 & $\begin{array}{l}0.214 \\
(0.57)\end{array}$ & $\begin{array}{l}0.250 \\
(0.64)\end{array}$ & $\begin{array}{l}-0.316 \\
(-1.02)\end{array}$ & $\begin{array}{l}-0.317 \\
(-1.02)\end{array}$ & $\begin{array}{c}-0.446^{* *} \\
(-2.06)\end{array}$ & $\begin{array}{c}-0.420^{*} \\
(-1.91)\end{array}$ \\
\hline Maturity & $\begin{array}{l}-1.501 \\
(-0.90)\end{array}$ & $\begin{array}{l}-1.528 \\
(-0.91)\end{array}$ & $\begin{array}{c}-4.280 * * * \\
(-2.79)\end{array}$ & $\begin{array}{c}-4.297 * * * \\
(-2.78)\end{array}$ & $\begin{array}{c}-2.771 * * * \\
(-2.76)\end{array}$ & $\begin{array}{c}-2.790 * * * \\
(-2.77)\end{array}$ \\
\hline $\mathrm{EE}$ & & $\begin{array}{l}-2.197 \\
(-0.53)\end{array}$ & & $\begin{array}{l}-2.673 \\
(-0.72)\end{array}$ & & $\begin{array}{l}-5.606 \\
(-0.98)\end{array}$ \\
\hline EU & & $\begin{array}{l}-0.855 \\
(-0.19)\end{array}$ & & $\begin{array}{l}1.862 \\
(0.25)\end{array}$ & & $\begin{array}{l}-3.664 \\
(-0.68)\end{array}$ \\
\hline$\Delta$ Rating $* \mathrm{EE}$ & & $\begin{array}{l}3.358 \\
(1.42)\end{array}$ & & $\begin{array}{c}3.995^{*} \\
(1.82)\end{array}$ & & $\begin{array}{c}3.435^{* * *} \\
(2.04)\end{array}$ \\
\hline$\Delta$ Rating $*$ EU & & $\begin{array}{c}3.993 * \\
(1.75) \\
\end{array}$ & & $\begin{array}{l}1.415 \\
(0.41) \\
\end{array}$ & & $\begin{array}{l}1.171 \\
(0.74) \\
\end{array}$ \\
\hline $\begin{array}{l}\text { Observations } \\
\text { R-squared } \\
\text { country fe }\end{array}$ & $\begin{array}{c}304 \\
0.1047 \\
\text { Yes } \\
\end{array}$ & $\begin{array}{c}304 \\
0.1053 \\
\text { Yes }\end{array}$ & $\begin{array}{c}282 \\
0.1726 \\
\text { Yes } \\
\end{array}$ & $\begin{array}{c}282 \\
0.1750 \\
\text { Yes } \\
\end{array}$ & $\begin{array}{c}232 \\
0.2700 \\
\text { Yes }\end{array}$ & $\begin{array}{c}232 \\
0.2381 \\
\text { Yes }\end{array}$ \\
\hline
\end{tabular}


Table 3. Continued.

Panel II: CRAs negative events

\begin{tabular}{|c|c|c|c|c|c|c|}
\hline \multirow[b]{2}{*}{ VARIABLES } & \multicolumn{2}{|c|}{ S\&P } & \multicolumn{2}{|c|}{ Moody's } & \multicolumn{2}{|c|}{ Fitch } \\
\hline & Eq.(1a) & Eq.(1b) & Eq.(1a) & Eq.(1b) & Eq.(1a) & Eq.(1b) \\
\hline$\Delta$ Rating & $\begin{array}{c}3.926 * * * \\
(2.81)\end{array}$ & $\begin{array}{c}3.860 * * * \\
(2.76)\end{array}$ & $\begin{array}{l}-2.039 \\
(-0.57)\end{array}$ & $\begin{array}{l}-1.907 \\
(-0.53)\end{array}$ & $\begin{array}{c}2.770 * * \\
(2.30)\end{array}$ & $\begin{array}{c}2.725 * * \\
(2.29)\end{array}$ \\
\hline Identifier & $\begin{array}{l}3.903 \\
(1.01)\end{array}$ & & $\begin{array}{l}-2.997 \\
(-0.41)\end{array}$ & & & \\
\hline$\Delta$ Rating* Identifier & $\begin{array}{l}-0.943 \\
(-0.48)\end{array}$ & & $\begin{array}{c}6.964 * \\
(1.69)\end{array}$ & & $\begin{array}{l}1.816 \\
(1.08)\end{array}$ & \\
\hline Rating58 & $\begin{array}{c}0.684 * * \\
(2.09)\end{array}$ & $\begin{array}{c}0.670 * * \\
(2.05)\end{array}$ & $\begin{array}{l}0.290 \\
(0.60)\end{array}$ & 0.518 & $\begin{array}{l}0.023 \\
(0.09)\end{array}$ & $\begin{array}{l}0.005 \\
(0.02)\end{array}$ \\
\hline Maturity & -2.361 & -2.396 & -0.689 & -1.051 & $-3.247^{*}$ & -2.538 \\
\hline & $(-1.32)$ & $(-1.33)$ & $(-0.22)$ & $(-0.30)$ & $(-1.84)$ & $(-1.43)$ \\
\hline $\mathrm{EE}$ & & $\begin{array}{l}3.235 \\
(0.59)\end{array}$ & & $\begin{array}{l}-2.399 \\
(-0.32)\end{array}$ & & $\begin{array}{l}-2.527 \\
(-0.47)\end{array}$ \\
\hline EU & & $\begin{array}{l}3.765 \\
(0.86)\end{array}$ & & $\begin{array}{l}9.669 \\
(0.49)\end{array}$ & & $\begin{array}{l}-2.930 \\
(-0.74)\end{array}$ \\
\hline$\Delta$ Rating *EE & & $\begin{array}{l}-0.528 \\
(-0.21)\end{array}$ & & $\begin{array}{l}6.639 \\
(1.58)\end{array}$ & & $\begin{array}{c}4.091 * * \\
(1.99)\end{array}$ \\
\hline$\Delta$ Rating $* E U$ & & $\begin{array}{r}-1.137 \\
(-0.48) \\
\end{array}$ & & $\begin{array}{l}8.301 \\
(1.02) \\
\end{array}$ & & $\begin{array}{r}-0.857 \\
(-0.41) \\
\end{array}$ \\
\hline $\begin{array}{l}\text { Observations } \\
\text { R-squared } \\
\text { country fe } \\
\end{array}$ & $\begin{array}{c}388 \\
0.1326 \\
\text { Yes } \\
\end{array}$ & $\begin{array}{c}388 \\
0.1323 \\
\text { Yes } \\
\end{array}$ & $\begin{array}{c}208 \\
0.2554 \\
\text { Yes } \\
\end{array}$ & $\begin{array}{c}208 \\
0.2604 \\
\text { Yes } \\
\end{array}$ & $\begin{array}{c}232 \\
0.2975 \\
\text { Yes } \\
\end{array}$ & $\begin{array}{c}232 \\
0.3170 \\
\text { Yes } \\
\end{array}$ \\
\hline
\end{tabular}

Note: This table presents the estimated coefficients and robust z-statistics in parentheses from specifications of Eq. (1a) and Eq. (1b). The dataset consists of daily positive and negative sovereign events by S\&P, Moody's and Fitch based in 58-CCR rating scale for 70 countries during Jan 2006-June 2016. For every event observation there is a randomly selected non-event observation. The dependent variable is $\Delta$ Yield which measures, in basis points, the changes in the window [0, +1$]$ sovereign yield spreads towards the benchmark US bonds on a particular sovereign bond $\mathrm{i}$ on the event day t. $\triangle$ Rating is the change in sovereign issuer CCR by one of the three CRAs coded as absolute ordinal values 1 (1-CCR), 2 (2-CCR) and 3 (>2-CCR), and 0 (no change). Identifier dummy equals 1 after the endorsement rules introduced by ESMA took effect on April 30 2012, and 0 otherwise. Rating58 represents sovereign's CCR taking values 1-58. Maturity is bond's time to maturity. EE (EU) takes the value of 1 if the rating of sovereign i is EU endorsed (EU originated) in the post-identifier period (30 April 2012), 0 otherwise. Year (country) fixed effects are included ("yes"). We estimate Eq. (1a) and (1b) separately for positive and negative events with absolute values (Panel I and II) for interpretation reasons. ***, **, * are significance levels at $1 \%, 5 \%$ and $10 \%$. 
Table 4. Statistical differences between rating change coefficients in the pre and post-identifier periods: S\&P

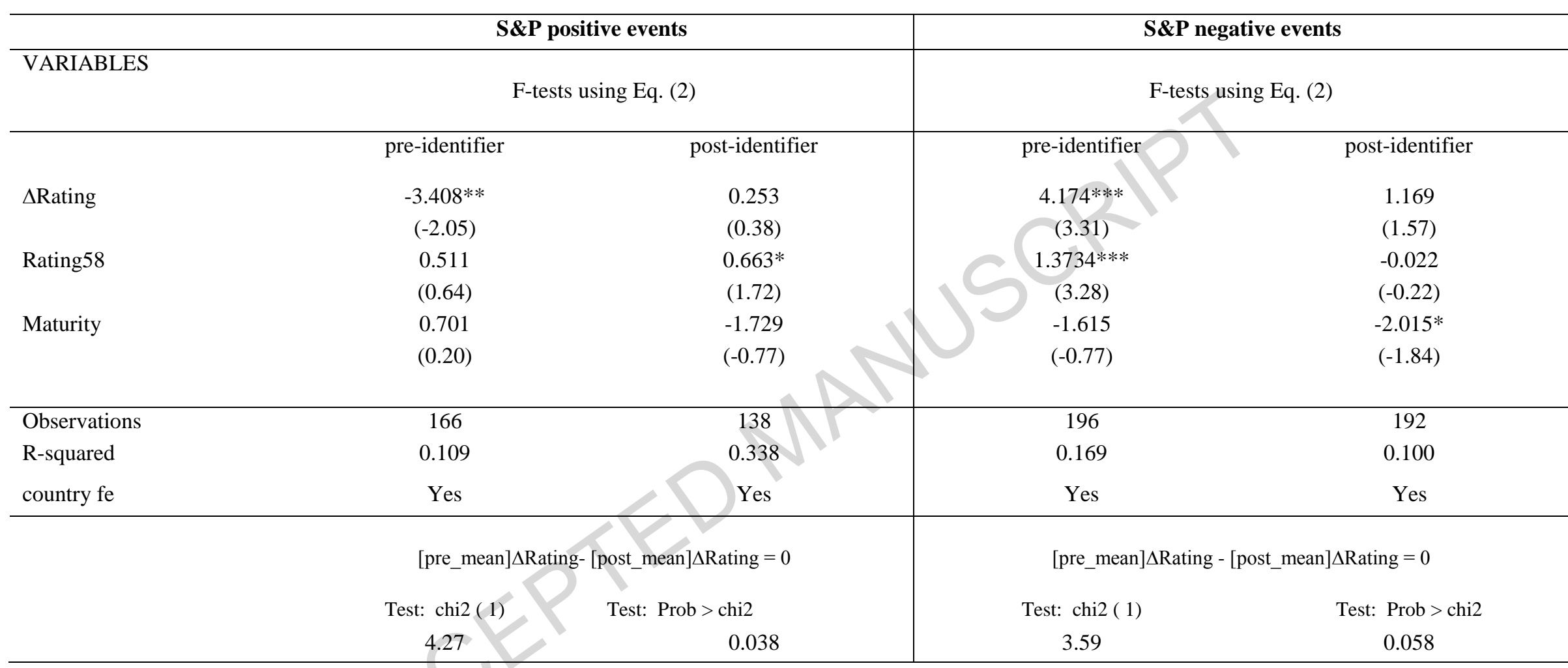

Note: This table presents the estimated coefficients and robust z-statistics in parentheses from specification of Eq. (2) using Ordinary Least Squares followed by the F-test which compares the statistical difference between $\Delta$ Rating coefficients in two sample periods. The credit rating dataset consists of daily positive and negative sovereign events by S\&P based on 58-CCR rating scale for 66 countries during pre-identifier (Jan 2006-April 2012) and post-identifier (May 2012-June 2016) periods. For every event observation there is a randomly selected non-event observation. The dependent variable is $\Delta$ Yield which measures, in basis points, the changes in the window $[0,+1]$ sovereign yield spreads towards the benchmark US bonds on a particular sovereign bond i on the event day t. The independent variables are defined in Table 3. F-test conducted using 'suest' command in STATA. Country fixed effects are included ("yes"). We estimate Eq. (2) separately for positive and negative events with absolute values for interpretation reasons. ***, **,* are significance levels at $1 \%, 5 \%$ and $10 \%$. 
Table 5. Statistical differences between rating change coefficients in the pre and post-identifier periods: Moody's

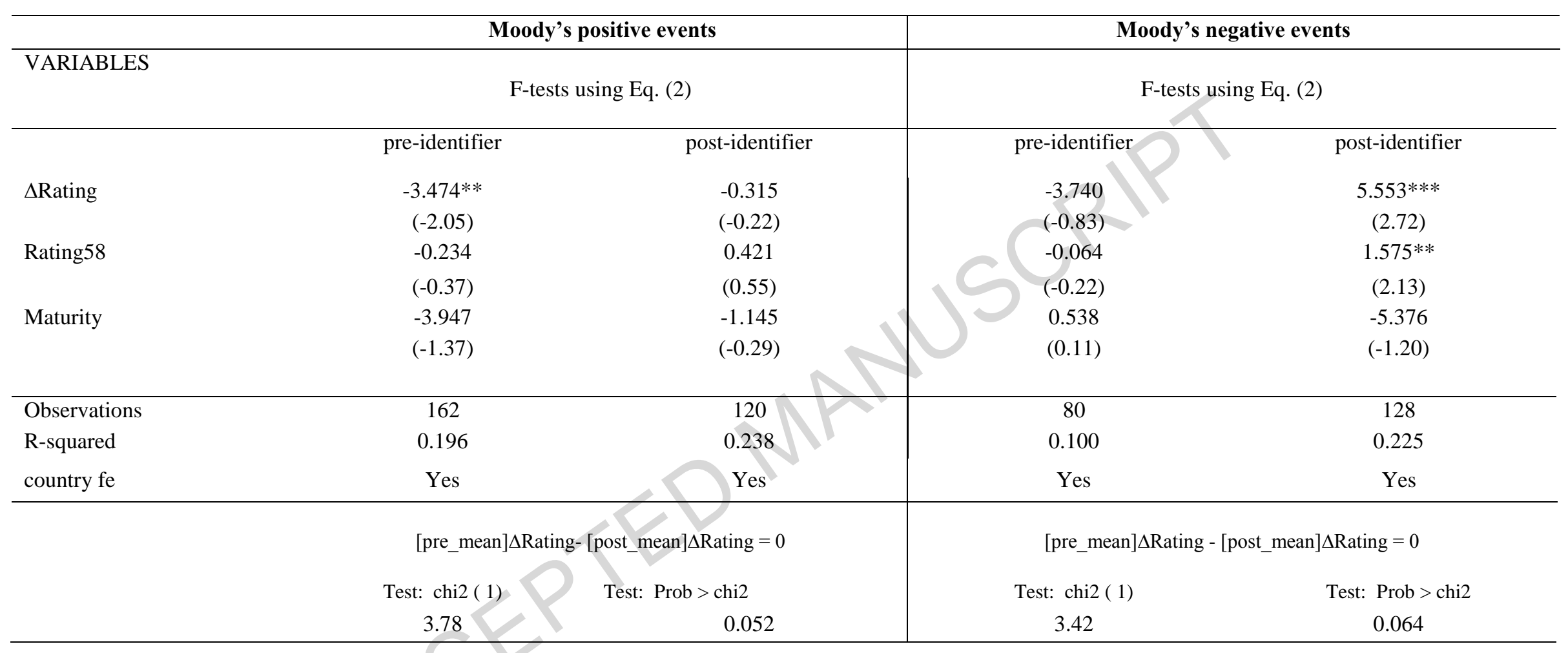

Note: This table presents the estimated coefficients and robust z-statistics in parentheses from specification of Eq. (2) using Ordinary Least Squares followed by the F-test which compares the statistical difference between $\Delta$ Rating coefficients in two sample periods. The credit rating dataset consists of daily positive and negative sovereign events by Moody's based on 58-CCR rating scale for 54 countries during pre-identifier (Jan 2006-April 2012) and post-identifier (May 2012-June 2016) periods. For every event observation there is a randomly selected non-event observation. The dependent variable is $\Delta$ Yield which measures, in basis points, the changes in the window $[0,+1]$ sovereign yield spreads towards the benchmark US bonds on a particular sovereign bond i on the event day t. The independent variables are defined in Table 3. F-test conducted using 'suest' command in STATA. Country fixed effects are included ("yes"). We estimate Eq. (2) separately for positive and negative events with absolute values for interpretation reasons. ***, **, * are significance levels at $1 \%, 5 \%$ and $10 \%$. 
Table 6. Statistical differences between rating change coefficients in the pre and post-identifier periods: Fitch

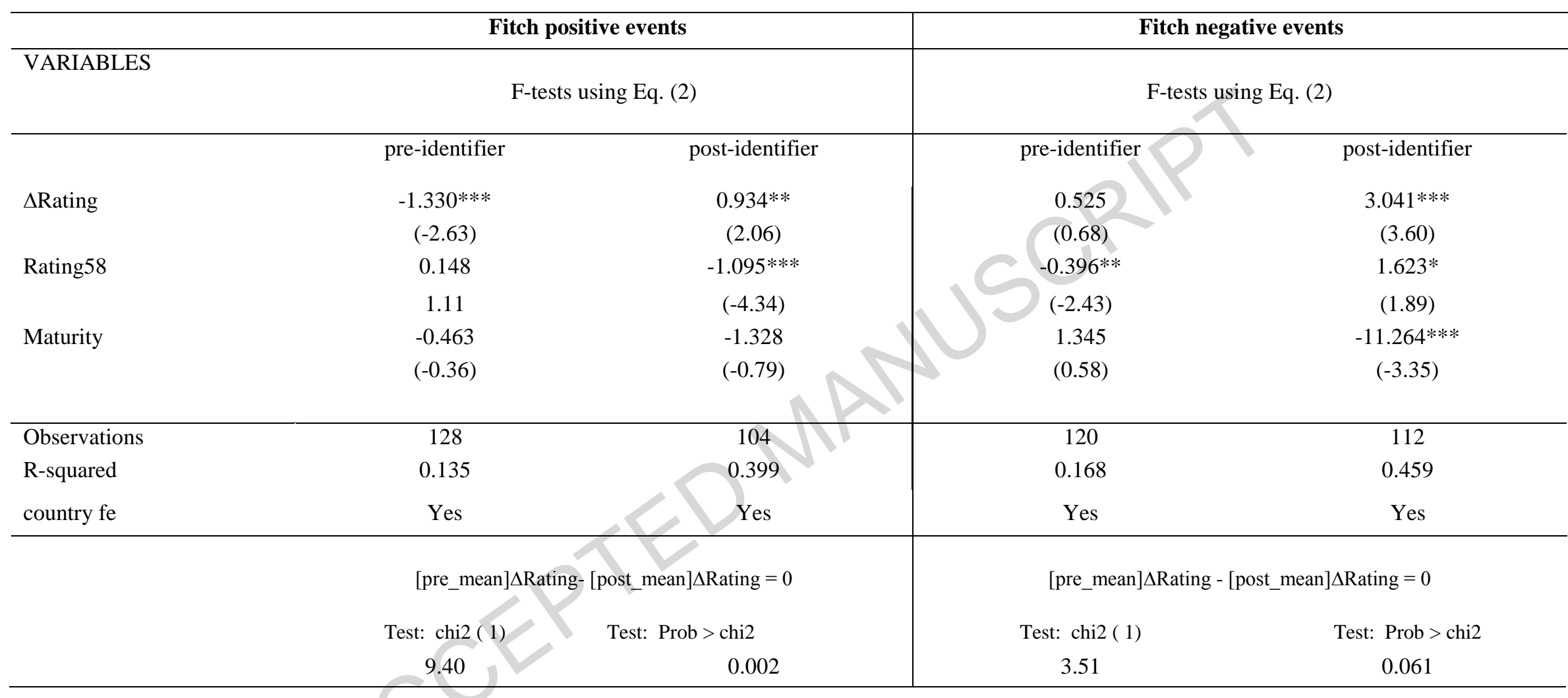

Note: This table presents the estimated coefficients and robust z-statistics in parentheses from specification of Eq. (2) using Ordinary Least Squares followed by the F-test which compares the statistical difference between $\Delta$ Rating coefficients in two sample periods. The credit rating dataset consists of daily positive and negative sovereign events by Fitch based on 58-CCR rating scale for 51 countries during pre-identifier (Jan 2006-April 2012) and post-identifier (May 2012-June 2016) periods. For every event observation there is a randomly selected non-event observation. The dependent variable is $\Delta$ Yield which measures, in basis points, the changes in the window $[0,+1]$ sovereign yield spreads towards the benchmark US bonds on a particular sovereign bond $i$ on the event day t. The independent variables are defined in Table 3. F-test conducted using 'suest' command in STATA. Country fixed effects are included ("yes). We estimate Eq. (2) separately for positive and negative events with absolute values for interpretation reasons. ***, **,* are significance levels at $1 \%, 5 \%$ and $10 \%$. 
Table 7. Statistical differences between rating change coefficients by analyst location, May 2012-June 2016: S\&P

\begin{tabular}{|c|c|c|c|c|}
\hline & \multicolumn{2}{|c|}{ S\&P positive events } & \multicolumn{2}{|c|}{ S\&P negative events } \\
\hline \multirow{3}{*}{ VARIABLES } & \multirow{2}{*}{\multicolumn{2}{|c|}{ F-tests using Eq. (2) }} & \multirow{2}{*}{\multicolumn{2}{|c|}{ F-tests using Eq. (2) }} \\
\hline & & & & \\
\hline & EE sub-sample & EU sub-sample & EE sub-samp & EU sub-sample \\
\hline \multirow[t]{2}{*}{$\Delta$ Rating } & 0.503 & -0.101 & $5.295 *$ & 0.351 \\
\hline & $(1.34)$ & $(-0.19)$ & ( & $(0.40)$ \\
\hline \multirow[t]{2}{*}{ Rating58 } & $0.251^{* *}$ & $1.104 *$ & $1.342 *$ & $-2.382^{*}$ \\
\hline & $(1.96)$ & (1.76) & $(1.75)$ & $(-1.72)$ \\
\hline \multirow[t]{2}{*}{ Maturity } & $-1.933 *$ & -0.237 & $-8.385 * * *$ & -2.773 \\
\hline & $(-1.82)$ & $(-0.10)$ & $(-2.81)$ & $(-0.89)$ \\
\hline \multirow{6}{*}{$\begin{array}{l}\text { Observations } \\
\text { R-squared } \\
\text { country fe }\end{array}$} & 56 & 82 & 84 & 116 \\
\hline & 0.331 & 0.301 & 0.128 & 0.378 \\
\hline & Yes & yes & Yes & Yes \\
\hline & [EEsample_mean] & le_mean $] \Delta$ Rating $=$ & [EEsample_mean] & mean $] \Delta$ Rating $=0$ \\
\hline & Test: chi2 ( & $>$ chi2 & Test: chi2 ( 1$)$ & Test: Prob > chi2 \\
\hline & 0.83 & 0.360 & 2.77 & 0.095 \\
\hline
\end{tabular}

Note: This table presents the estimated coefficients and robust z-statistics in parentheses from specification of Eq. (2) using Ordinary Least Squares followed by the F-test which compares the statistical difference between $\Delta$ Rating coefficients for the two groups of countries (EU vs EU identifier) in the postidentifier sample period (May 2012-June 2016). The credit rating dataset consists of daily positive and negative sovereign events by S\&P based on 58-CCR rating scale. EU (EE) sub-sample consists of sovereign rating events with EU (EE) identifiers. For every event observation there is a randomly selected nonevent observation. The dependent variable is $\Delta$ Yield which measures, in basis points, the changes in the window $[0,+1]$ sovereign yield spreads towards the benchmark US bonds on a particular sovereign bond i on the event day t. The independent variables are defined in Table 3. F-test conducted using 'suest' command in STATA. Country fixed effects are included ("yes"). We estimate Eq. (2) separately for positive and negative events with absolute values for interpretation reasons. $* * * * * *$ are significance levels at $1 \%, 5 \%$ and $10 \%$. 
Table 8. Statistical differences between rating change coefficients by analyst location, May 2012-June 2016: Moody's

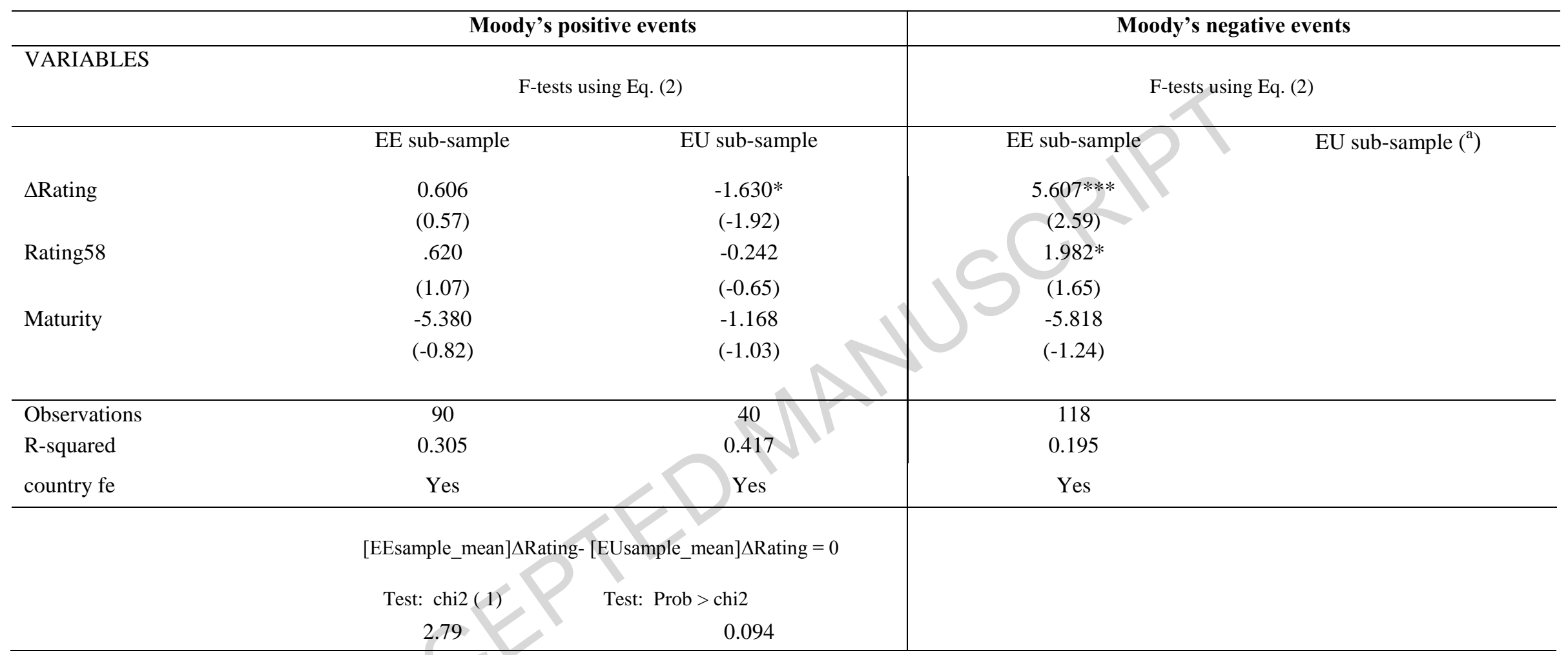

Note: This table presents the estimated coefficients and robust z-statistics in parentheses from specification of Eq. (2) using Ordinary Least Squares followed by the F-test which compares the statistical difference between $\Delta$ Rating coefficients for the two groups of countries (EU vs EU identifier) in the postidentifier sample period (May 2012-June 2016). The credit rating dataset consists of daily positive and negative sovereign events by Moody's based on 58CCR rating scale. EU (EE) sub-sample consists of sovereign rating events with EU (EE) identifiers. For every event observation there is a randomly selected non-event observation. The dependent variable is $\Delta$ Yield which measures, in basis points, the changes in the window $[0,+1]$ sovereign yield spreads towards the benchmark US bonds on a particular sovereign bond i on the event day t. The independent variables are defined in Table 3. F-test conducted using 'suest' command in STATA. Country fixed effects are included ("yes"). We estimate Eq. (2) separately for positive and negative events with absolute values for interpretation reasons. $* * * * * *$ are significance levels at $1 \%, 5 \%$ and $10 \%$.

$\left.{ }^{(}\right)$There are only 7 negative events by Moody's in the EU post-identifier sub-sample. The results in this case are not reliable and we have not reported the Ftest. 
Table 9. Statistical differences between rating change coefficients by analyst location, May 2012-June 2016: Fitch

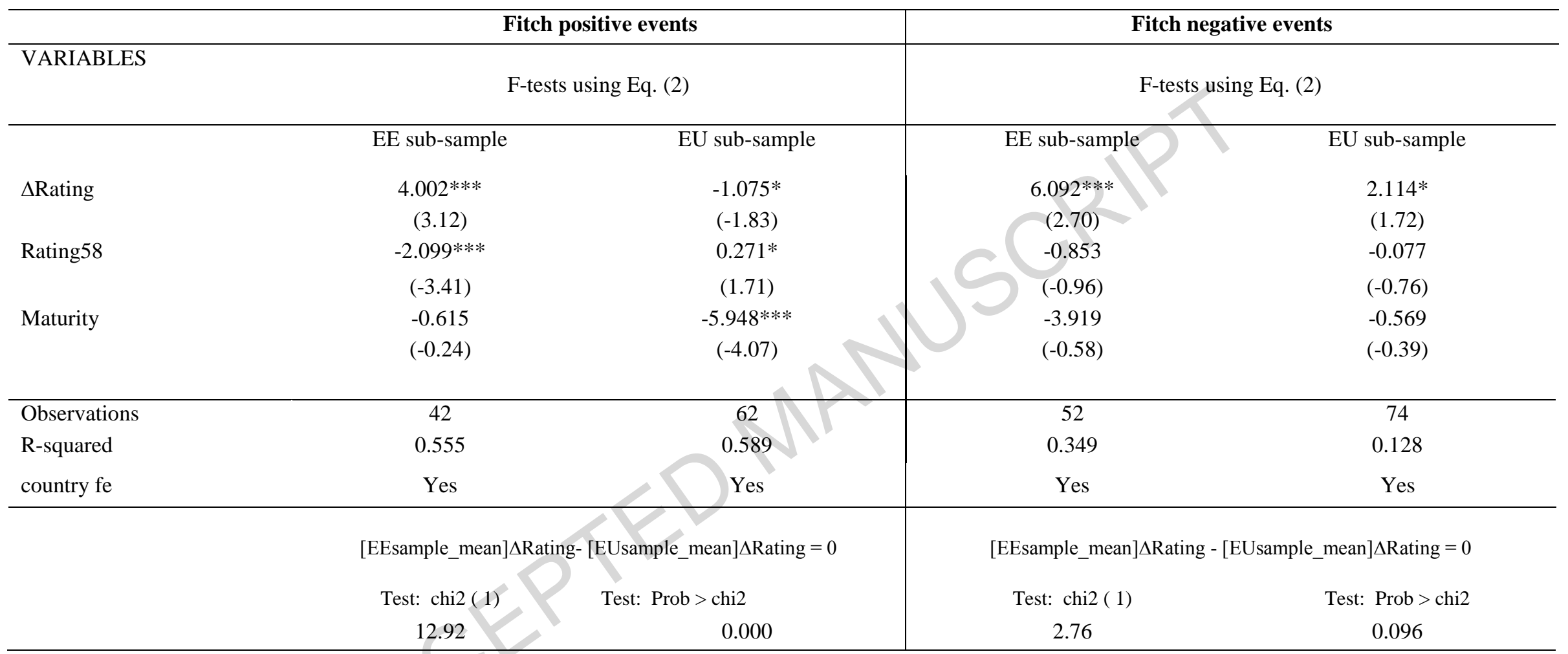

Note: This table presents the estimated coefficients and robust z-statistics in parentheses from specification of Eq. (2) using Ordinary Least Squares followed by the F-test which compares the statistical difference between $\Delta$ Rating coefficients for the two groups of countries (EU vs EU identifier) in the postidentifier sample period (May 2012-June 2016). The credit rating dataset consists of daily positive and negative sovereign events by Fitch based on 58-CCR rating. EU (EE) sub-sample consists of sovereign rating events with EU (EE) identifiers. For every event observation there is a randomly selected non-event observation. The dependent variable is $\Delta$ Yield which measures, in basis points, the changes in the window $[0,+1]$ sovereign yield spreads towards the benchmark US bonds on a particular sovereign bond i on the event day t. The independent variables are defined in Table 3. F-test conducted using 'suest' command in STATA. Country fixed effects are included ("yes"). We estimate Eq. (2) separately for positive and negative events with absolute values for interpretation reasons. $* * * * * *$ are significance levels at $1 \%, 5 \%$ and $10 \%$. 
Table 10. Difference-in-Differences estimation: Treatment versus control countries

\begin{tabular}{|c|c|c|c|c|c|c|}
\hline VARIABLES & S\&P + & S\&P - & Moody's + & Moody's - & Fitch + & Fitch - \\
\hline \multirow[t]{2}{*}{$\Delta$ Rating*EUB } & $-9.026 * * *$ & 1.214 & 0.528 & -3.210 & -2.128 & $2.167^{*}$ \\
\hline & $(-2.95)$ & $(0.77)$ & $(0.12)$ & $(-0.43)$ & $(-1.09)$ & (1.67) \\
\hline \multirow[t]{2}{*}{$\Delta$ Rating*EEB } & $-3.297 * *$ & 0.660 & $-4.702 * *$ & -1.182 & 0.785 & $7.582 * * *$ \\
\hline & $(-2.14)$ & $(0.27)$ & $(-2.20)$ & $(-0.31)$ & $(0.61)$ & (3.16) \\
\hline \multirow[t]{2}{*}{$\Delta$ Rating*EE } & 2.722 & 2.288 & $5.005^{* *}$ & & 0.391 & -0.601 \\
\hline & $(1.27)$ & $(0.81)$ & (1.98) & (1.38) & $(0.25)$ & $(-0.23)$ \\
\hline \multirow[t]{2}{*}{$\Delta$ Rating*EU } & $8.946^{* * *}$ & 1.413 & -1.058 & 12.646 & 1.237 & -1.330 \\
\hline & $(2.70)$ & $(0.66)$ & $(-0.22)$ & (1.49) & $(0.59)$ & $(-0.71)$ \\
\hline \multirow[t]{2}{*}{ Rating58 } & 0.184 & 0.468 & -0.297 & 0.490 & $-0.371^{*}$ & 0.060 \\
\hline & $(0.50)$ & $(1.63)$ & $(-0.91)$ & $(1.22)$ & $(-1.77)$ & $(0.27)$ \\
\hline \multirow[t]{2}{*}{ Maturity } & -2.131 & -2.515 & $-3.893 * *$ & -0.250 & $-2.558 * *$ & -2.239 \\
\hline & $(-1.27)$ & $(-1.39)$ & $(-2.50)$ & $(-0.08)$ & $(-2.55)$ & $(-1.30)$ \\
\hline Observations & 304 & 388 & 282 & 208 & 232 & 232 \\
\hline R-squared & 0.1221 & 0.1134 & 0.1953 & 0.2585 & 0.2353 & 0.3368 \\
\hline country fe & Yes & Yes & Yes & Yes & Yes & Yes \\
\hline
\end{tabular}

Note: This table presents the estimated coefficients and robust z-statistics in parentheses from specifications of Eq. (3) using Ordinary Least Squares. The credit rating dataset consists of daily positive and negative sovereign events by: S\&P, Moody's and Fitch based on 58-CCR rating scale for 70 countries during Jan 2006-June 2016. For every event observation there is a randomly selected non-event observation. The dependent variable is $\Delta$ Yield which measures, in basis points, the changes in the window $[0,+1]$ sovereign yield spreads towards the benchmark US bonds on a particular sovereign bond i on the event day t. $E E B$ ('EE' Before) equals to 1 during the pre-identifier period for those countries which have the 'EE' identifier in the post-identifier period, and 0 otherwise. $E U B$ ('EU' Before) equals to 1 during the pre-identifier period for those countries which have the 'EU' identifier in the post-identifier period, and 0 otherwise. $E E(E U)$ takes the value of 1 if the rating of sovereign i is EU endorsed (EU originated) in the post-identifier period (30 April 2012 ), 0 otherwise. Rating58 represents sovereign's CCR taking values 1-58. Maturity is bond's time to maturity. Country fixed effects are included ("yes"). We estimate Eq. (3) separately for positive and negative events with absolute values for interpretation reasons. ***,**,* are significance levels at $1 \%, 5 \%$ and $10 \%$ 


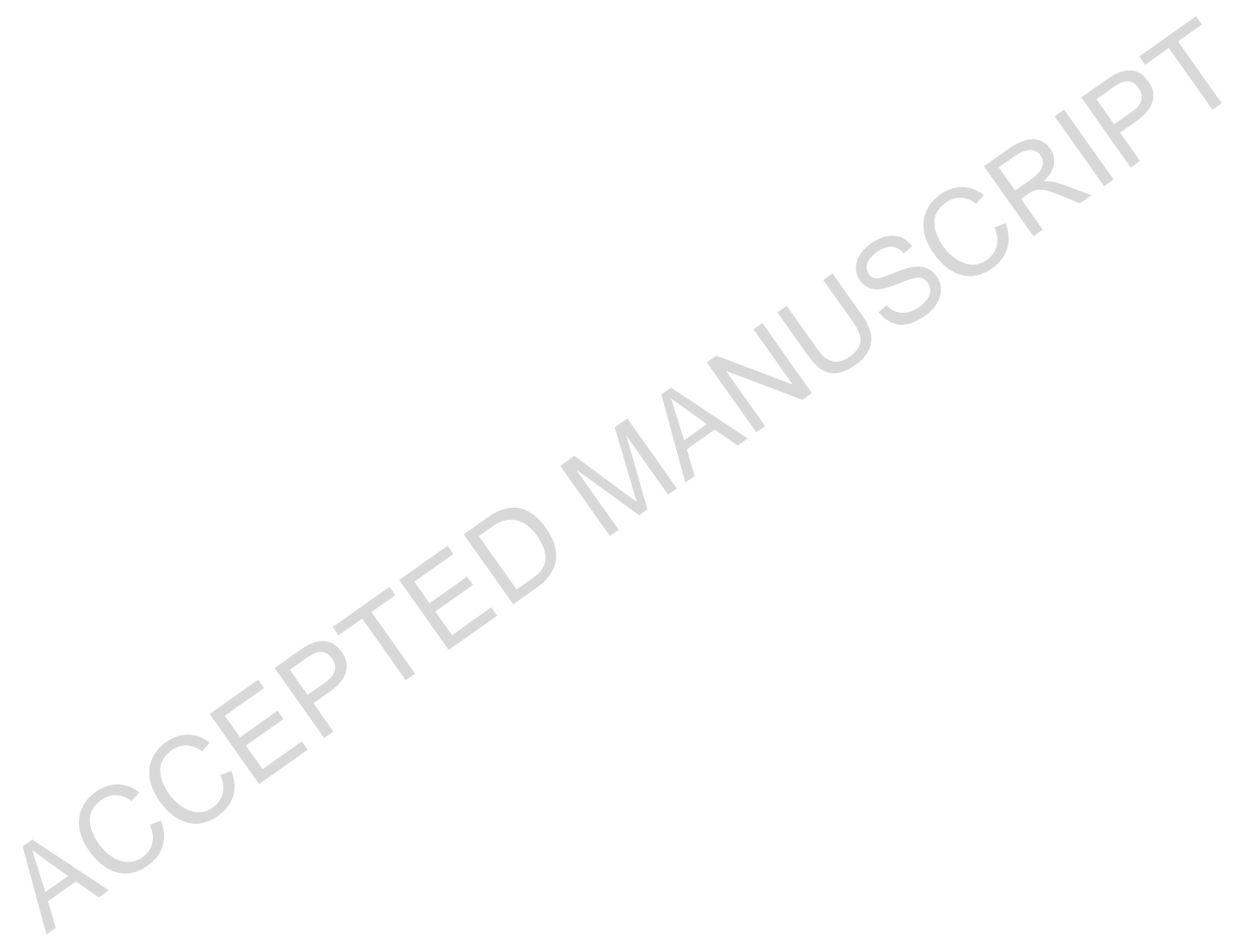


Appendix A: Credit rating scale

\begin{tabular}{|c|c|c|c|c|}
\hline Rating symbols & Outlook/Watch & $\begin{array}{c}58- \\
\text { point }\end{array}$ & Adjustments & $\begin{array}{c}\text { 58-point CCR } \\
\text { scale } \\
\end{array}$ \\
\hline AAA/Aaa & stable watch/outlook & & 0 & 58 \\
\hline AAA/Aaа & negative outlook & 58 & -1 & 57 \\
\hline AAA/Aaa & negative watch & & -2 & 56 \\
\hline $\mathrm{AA}+/ \mathrm{Aa} 1$ & positive watch & & 2 & 57 \\
\hline $\mathrm{AA}+/ \mathrm{Aa} 1$ & positive outlook & & 1 & 56 \\
\hline $\mathrm{AA}+/ \mathrm{Aa} 1$ & stable watch/outlook & 55 & 0 & 55 \\
\hline $\mathrm{AA}+/ \mathrm{Aa} 1$ & negative outlook & & -1 & 54 \\
\hline $\mathrm{AA}+/ \mathrm{Aa} 1$ & negative watch & & -2 & 53 \\
\hline $\mathrm{AA} / \mathrm{Aa} 2$ & positive watch & & 2 & 54 \\
\hline $\mathrm{AA} / \mathrm{Aa} 2$ & positive outlook & & 1 & 53 \\
\hline $\mathrm{AA} / \mathrm{Aa} 2$ & stable watch/outlook & 52 & 0 & 52 \\
\hline $\mathrm{AA} / \mathrm{Aa} 2$ & negative outlook & & -1 & 51 \\
\hline $\mathrm{AA} / \mathrm{Aa} 2$ & negative watch & & -2 & 50 \\
\hline $\mathrm{AA}-/ \mathrm{Aa} 3$ & positive watch & & 2 & 51 \\
\hline AA-/Aa3 & positive outlook & & 1 & 50 \\
\hline $\mathrm{AA}-/ \mathrm{Aa} 3$ & stable watch/outlook & 49 & 0 & 49 \\
\hline AA-/Aa3 & negative outlook & & -1 & 48 \\
\hline AA-/Aa3 & negative watch & & -2 & 47 \\
\hline$[\ldots \ldots]$ & {$[\ldots \ldots]$} & & {$[\ldots \ldots]$} & {$[\ldots \ldots]$} \\
\hline $\mathrm{B}-/ \mathrm{B} 3$ & positive watch & & 2 & 15 \\
\hline B-/B3 & positive outlook & & 1 & 14 \\
\hline B-/B3 & stable watch/outlook & 13 & 0 & 13 \\
\hline B-/B3 & negative outlook & & -1 & 12 \\
\hline B-/B3 & negative watch & & -2 & 11 \\
\hline $\mathrm{CCC}+/ \mathrm{Caa} 1$ & positive watch & & 2 & 12 \\
\hline $\mathrm{CCC}+/ \mathrm{Caa} 1$ & positive outlook & & 1 & 11 \\
\hline $\mathrm{CCC}+/ \mathrm{Caa} 1$ & stable watch/outlook & 10 & 0 & 10 \\
\hline $\mathrm{CCC}+/ \mathrm{Caa} 1$ & negative outlook & & -1 & 9 \\
\hline $\mathrm{CCC}+/ \mathrm{Caa} 1$ & negative watch & & -2 & 8 \\
\hline $\mathrm{CCC} / \mathrm{Caa} 2$ & positive watch & & 2 & 9 \\
\hline $\mathrm{CCC} / \mathrm{Caa} 2$ & positive outlook & & 1 & 8 \\
\hline $\mathrm{CCC} / \mathrm{Caa} 2$ & stable watch/outloc & 7 & 0 & 7 \\
\hline $\mathrm{CCC} / \mathrm{Caa} 2$ & negative outlook & & -1 & 6 \\
\hline $\mathrm{CCC} / \mathrm{Caa} 2$ & negative watch & & -2 & 5 \\
\hline CCC-/Caa3 & positive watch & & 2 & 6 \\
\hline CCC-/Caa3 & positive outlook & & 1 & 5 \\
\hline CCC-/Caa3 & stable watch/outlook & 4 & 0 & 4 \\
\hline CCC-/Caa3 & negative outlook & & -1 & 3 \\
\hline CCC-/Caa3 & negative watch & & -2 & 2 \\
\hline $\begin{array}{l}\mathrm{CC}, \mathrm{SD}, \mathrm{D} / \\
\mathrm{Ca}, \mathrm{C} / \mathrm{RD}, \mathrm{D}\end{array}$ & & 1 & & 1 \\
\hline
\end{tabular}

This Table presents the transformation of the alphabetical rating scale to the 58-point CCR numerical rating scale. 
- We examine the impact of ESMA credit rating identifiers on the quality of ratings

- The ESMA requirement for rating identifiers yields varying outcomes

- The rating quality associated with Moody's downgrades improves

- Upgrades by S\&P, Moody’s and Fitch are of lower informational value

- Analyst location does not reveal any consistent effect on changes in rating quality 